\title{
A Personalized Framework for Dynamic Modeling of Disease Trajectories in Chronic Lymphocytic Leukemia
}

\author{
Savvopoulos S. ${ }^{1}$, Misener R. ${ }^{2}$, Panoskaltsis N. ${ }^{3}$, Pistikopoulos E. N. ${ }^{1,4}$ and Mantalaris A. ${ }^{1}$ \\ ${ }^{1}$ Department of Chemical Engineering, Imperial College London, South Kensington Campus, London, UK \\ ${ }^{2}$ Department of Computing, Imperial College London, South Kensington Campus, London, UK \\ ${ }^{3}$ Department of Haematology, Imperial College London, Northwick Park and St. Mark's Campus, London, UK \\ ${ }^{4}$ Department of Chemical Engineering, Texas A\&M University, College Station TX, USA
}

\begin{abstract}
Chronic Lymphocytic Leukemia (CLL) is the most common peripheral blood and bone marrow cancer in the developed world. This manuscript proposes mathematical model equations representing the disease dynamics of B-cell CLL. We interconnect delay differential cell cycle models in each of the tumor-involved disease centers using physiologically-relevant cell migration. We further introduce 5 hypothetical case studies representing CLL heterogeneity commonly seen in clinical practice and demonstrate how the proposed CLL model framework may capture disease pathophysiology across patient types. We conclude by exploring the capacity of the proposed temporally- and spatially-distributed model to capture the heterogeneity of CLL disease progression. By using Global Sensitivity Analysis, the critical parameters influencing disease trajectory over space and time are: (i) the initial number of CLL cells in peripheral blood, the number of involved lymph nodes, the presence and degree of splenomegaly; (ii) the migratory fraction of nonproliferating as well as proliferating CLL cells from bone marrow into blood and of proliferating CLL cells from blood into lymph nodes; (iii) the parameters inducing nonproliferative cells to proliferate. The proposed model offers a practical platform which may be explored in future personalized patient protocols once validated.
\end{abstract}

\section{INTRODUCTION}

Chronic Lymphocytic Leukemia (CLL) is the most common peripheral blood and bone marrow cancer in the developed world, usually afflicting older individuals [1]. It is a heterogeneous disease consisting of abnormal proliferation and reduced apoptosis in mutated clones, most commonly of mature B-cells, resulting in accumulation in 4 compartments: the bone marrow, peripheral blood, lymph nodes and spleen. Initial chromosomal mutations differ between patients and malignant transformations

Support from ERC-BioBlood \#340719, a RAEng Research Fellowship to R.M., the Richard Thomas Leukaemia Research Fund, and the National Institute for Health Research Clinical Research Network: Cancer. R Misener: r.misenere imperial . ac . uk; +44 (0) 20759 48315 N Panoskaltsis: n.panoskaltsis@imperial.ac.uk progress variably. Subclonal mutations may arise and overtake the dominant clone because of other stressors, such as chemotherapy used to treat the original disease [2]. The site of primary CLL pathogenesis is the lymph nodes and/or bone marrow with cells then circulating in peripheral blood and homing preferentially towards bone marrow, lymph nodes, or spleen depending on expression of chemokine receptors or intracellular proteins [3]-[5]; this heterogeneity results in variable presentations of lymphocytosis, bone marrow failure, lymphadenopathy and splenomegaly $[6,7]$ with the clinical stages of disease defined using the Binet [8] or Rai [9] systems and WHO [10] criteria for diagnosis (Table 1). The disease typically progresses slowly with most CLL cells arrested in the resting (G0) or growth (G1) phases of the cell cycle [11]. Since CLL has defined mutations predictive of prognosis and a chronic trajectory often spanning decades, we hypothesize that mathematical models may characterize CLL disease dynamics with the potential to act as a framework for personalized treatment strategies.

Diverging from previous mathematical models for Bcell CLL (hereafter referred to as CLL), this manuscript presents the first personalized, physiologically-relevant mathematical framework modeling CLL with features that (1) consider each of the most relevant disease centers including those of bone marrow, peripheral blood, lymph nodes and spleen, (2) interconnect the affected tissues via descriptors for cell migration, (3) calculate migration rates between affected tissues and (4) provide a framework to predict CLL progression over the disease course, in the absence of treatment. This work belongs to an ongoing effort developing building blocks for modeling and optimizing biomedical systems [12] such as that for Acute Myeloid Leukemia [13, 14], Type 1 Diabetes Mellitus [15] and for the delivery of anesthesia [16, 17]. We previously performed a more limited global sensi- 
TABLE 1: Clinical Staging and Corresponding PB Lymphocyte Doubling Time (LDT) [8]-[10, 19, 20]

\begin{tabular}{|c|c|c|c|}
\hline \multirow{2}{*}{ Symptoms } & \multicolumn{2}{|r|}{ CLL Clinical Stage } & \multirow{2}{*}{$\begin{array}{l}\text { LDT [months } \\
\pm \text { SEM] }\end{array}$} \\
\hline & Rai & Binet & \\
\hline $\begin{array}{l}\text { Lymphocytosis } \\
\left(>5 \cdot 10^{9} \text { cells/L) }\right.\end{array}$ & \multicolumn{2}{|l|}{0} & \\
\hline $\begin{array}{l}\text { Lymphocytosis and nodal } \\
\text { involvement }\end{array}$ & I & $\begin{array}{l}\text { A }(<3 \text { areas of } \\
\text { lymph nodes })\end{array}$ & $69.6 \pm 20.5$ \\
\hline $\begin{array}{l}\text { Lymphocytosis and } \\
\text { organomegaly }\end{array}$ & II & $\begin{array}{l}\text { B (Lymphadenopathy } \\
\text { and splenomegaly) }\end{array}$ & $10.8 \pm 2.1$ \\
\hline Anemia $(\mathrm{Hgb}<11 \mathrm{~g} / \mathrm{dL})$ & III & \multirow{2}{*}{$\mathrm{C}$} & \multirow[b]{2}{*}{$10.8 \pm 4.4$} \\
\hline $\begin{array}{l}\text { Lymphocytosis and } \\
\text { thrombocytopenia (PLT }<\end{array}$ & $\frac{\mathrm{IV}}{11 / \mathrm{L})}$ & & \\
\hline
\end{tabular}

WHO classification: Lymphocytosis $\geq 5 \times 10^{9}$ cells/L for $\geq 3$ mon with Immunophenotype: SIG, $\mathrm{CIG}^{-/+}$, CD5, CD23, CD43, CD19, CD20, CD79a; Genetics: IgVH, trisomy 12, [del(13q14.1)], [del(11q)], [del(6q)], [del(17p)] SEM $\equiv$ Standard Error Mean

TABLE 2: Expected lymphocyte count ${ }^{\dagger}[21,22]$

\begin{tabular}{lrrrrr}
\hline \multirow{2}{*}{ Body Part } & Number of & Distri- & \multicolumn{3}{c}{$\%$ cell type } \\
\cline { 3 - 6 } & lymphocytes & bution & B & T & NK \\
\hline Blood (PB) & $10 \times 10^{9}$ & $2.2 \%$ & 25 & 70 & 5 \\
Lymph nodes (LN) & $190 \times 10^{9}$ & $41.3 \%$ & 20 & 70 & 10 \\
Spleen (S) & $70 \times 10^{9}$ & $15.2 \%$ & 50 & 40 & 10 \\
Gut Lymphoid Tissue & $20 \times 10^{9}$ & $4.3 \%$ & & & \\
Thymus & $50 \times 10^{9}$ & $10.9 \%$ & $<1$ & $>95$ & \\
Bone Marrow (BM) & $50 \times 10^{9}$ & $10.9 \%$ & 50 & 50 & \\
Other tissue & $70 \times 10^{9}$ & $15.2 \%$ & & & \\
\hline
\end{tabular}

${ }^{\dagger}$ Assuming a $70 \mathrm{~kg}$ human with $460 \times 10^{9}$ total lymphocytes

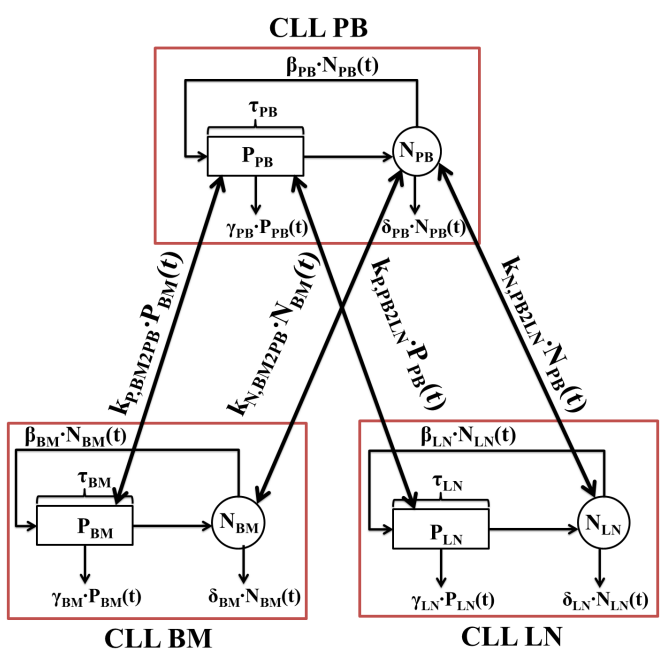

Fig. 1: CLL modeling framework incorporates the major disease compartments

tivity analysis than that described in Online Supplement Appendix F [18]; otherwise the manscript has all new material.

\section{Mathematical Model}

The model (Fig. 1) consists of 3 cell cycle models and the interconnectivity between them; we assume that CLL cells are distributed in bone marrow (BM), peripheral

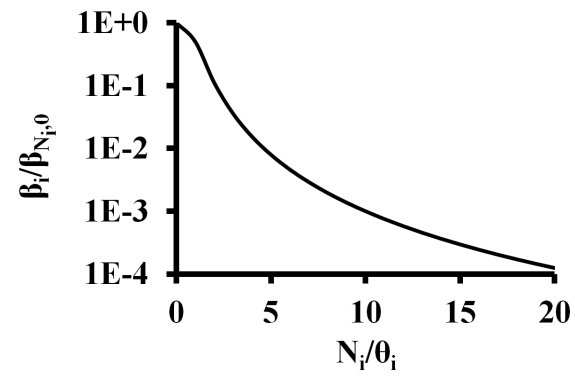

Fig. 2: Normalized feedback function (Eq 2) in semilogarithmic plot $(n=3)$ [23]

blood (PB), and lymph nodes (LN) and spleen (S) at the point of diagnosis and that $\mathrm{S}$ is aggregated with $\mathrm{LN}$.

\section{A. Chronic Lymphocytic Leukemia (CLL)}

Our model (Fig. 1) is a general framework which captures the following dynamics: as CLL cells proliferate in BM (as captured at diagnosis - the pre-diagnosis disease-initiating mutation(s) may occur in either LN or $\mathrm{S}$ and then populate $\mathrm{BM}$ ), the cells may either migrate to PB and then LN or stay in BM. It includes 3 cell cycles and migration rates for both proliferative $(P)$ and nonproliferative $(N)$ CLL cells from BM to PB (BM2PB) and then to $\mathrm{LN}$ (PB2LN); this model applies to naïve stage and Binet stages A - C (SN, SA, SB, SC). Eqs (1) - (12) represent the specific case where: (a) the Mackey [23] G0 model (Appendix A) is correct and (b) we have data regarding lymphocyte counts and proliferation in affected tissues (Tables $1 \& 2$ ). While we limit our analysis to a proliferating/non-proliferating model [23], an equivalent development could be constructed for a detailed G1 $\rightarrow \mathrm{S} \rightarrow \mathrm{G} 2 / \mathrm{M}$ cell cycle model, e.g., [24].

Before defining the 3 interconnected G0 models in Eqs (7) - (12), we define a time delay (Eq 1), proliferation feedback function (Eq $2 \& 3$ ), and the relationship between Ki-67 expression, i.e., percent proliferation, and cell numbers for each disease center $i \in\{\mathrm{BM}, \mathrm{PB}, \mathrm{LN}\}$ and disease stage $z \in\{\mathrm{SN}, \mathrm{SA}, \mathrm{SB}, \mathrm{SC}\}$.

$$
\begin{aligned}
N_{i, \tau_{i, z}} & =N_{i}\left(t-\tau_{i, z}\right) \\
\beta_{i}\left(N_{i}\right) & =\beta_{N_{i}, 0} \cdot \theta_{i}^{n_{i}} /\left(\theta_{i}^{n_{i}}+N_{i}^{n_{i}}\right) \\
\theta_{i} & =\theta_{i, 1, z}\left(t-t_{\mathrm{in}, z}\right)+\theta_{i, 2, z} \\
\operatorname{Ki}-67_{i} & =P_{i} /\left(P_{i}+N_{i}\right)
\end{aligned}
$$

In the Eq (2) feedback function, $\beta_{N_{i}, 0}$ is the maximum recruitment in each tissue [25]. Fig. 2 illustrates Eq (2) for $n=3$ and demonstrates that control parameter $\theta_{i}$ modulates recruitment from non-proliferative $\left(N_{i}\right)$ and proliferative $\left(P_{i}\right)$ phases. The $\theta_{i}$ value is larger in CLL proliferation centers, i.e., $\mathrm{BM}, \mathrm{LN}$ and $\mathrm{S}$, than in the accumulation compartment (PB) where the expression of proliferative marker Ki-67 is lowest [26]. 
The $\mathrm{BM}$ disease center has restricted volume $\left(\mathrm{BM}_{\max } \approx 13.5 \times 10^{11}\right.$ lymphocytes; Appendix B). Assuming that the normal lymphocyte count in BM remains constant, carrying capacity, $c c$, represents restricted volume [27], $a_{\mathrm{BM}}$ is the percentage of normal lymphocytes in BM (see Appendix B), and $C_{\mathrm{NC}, \mathrm{BM}}$ is the number of lymphocytes in normal BM (Table 2):

$$
\begin{aligned}
\% \mathrm{BM}_{\text {lymph }} & =\frac{C_{\mathrm{NC}, \mathrm{BM}}+N_{\mathrm{BM}}+P_{\mathrm{BM}}}{\frac{1}{a_{\mathrm{BM}}} C_{\mathrm{NC}, \mathrm{BM}}+P_{\mathrm{BM}}+N_{\mathrm{BM}}} \\
c c\left(N_{\mathrm{BM}}, P_{\mathrm{BM}}\right) & =1-\frac{C_{\mathrm{NC}, \mathrm{BM}}+N_{\mathrm{BM}}+P_{\mathrm{BM}}}{\mathrm{BM}_{\max }}
\end{aligned}
$$

BM Eqs $(7-8)$ hold $\forall z \in\{\mathrm{SN}, \mathrm{SA}, \mathrm{SB}, \mathrm{SC}\}$ :

$$
\begin{aligned}
& \frac{d N_{\mathrm{BM}}}{d t}=-\delta_{\mathrm{BM}, z} N_{\mathrm{BM}} \\
& -\beta_{\mathrm{BM}}\left(N_{\mathrm{BM}}\right) N_{\mathrm{BM}} c c\left(N_{\mathrm{BM}}, P_{\mathrm{BM}}\right)
\end{aligned}
$$

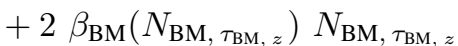

$$
\begin{aligned}
& e^{-\gamma_{\mathrm{BM}, z} \tau_{\mathrm{BM}, z}} \operatorname{cc}\left(N_{\mathrm{BM}}, P_{\mathrm{BM}}\right) \\
& -k_{\mathrm{N}, \mathrm{BM} 2 \mathrm{~PB}, z} N_{\mathrm{BM}} \\
& \frac{d P_{\mathrm{BM}}}{d t}=-\gamma_{\mathrm{BM}, z} P_{\mathrm{BM}} \\
& +\beta_{\mathrm{BM}}\left(N_{\mathrm{BM}}\right) N_{\mathrm{BM}} c c\left(N_{\mathrm{BM}}, P_{\mathrm{BM}}\right) \\
& -\beta_{\mathrm{BM}}\left(N_{\mathrm{BM}, \tau_{\mathrm{BM}, z}}\right) N_{\mathrm{BM}, \tau_{\mathrm{BM}, z}} \\
& e^{-\gamma_{\mathrm{BM}, z} \tau_{\mathrm{BM}, z}} \operatorname{cc}\left(N_{\mathrm{BM}}, P_{\mathrm{BM}}\right) \\
& -k_{\mathrm{P}, \mathrm{BM} 2 \mathrm{~PB}, z} P_{\mathrm{BM}}
\end{aligned}
$$

PB Eqs (9) \& (10) hold $\forall z \in\{$ SN, SA, SB, SC $\}$ :

$$
\begin{aligned}
\frac{d N_{\mathrm{PB}}}{d t}= & -\delta_{\mathrm{PB}, z} N_{\mathrm{PB}}-\beta_{\mathrm{PB}}\left(N_{\mathrm{PB}}\right) N_{\mathrm{PB}} \\
& +2 \beta_{\mathrm{PB}}\left(N_{\mathrm{PB}, \tau_{\mathrm{PB}, z}}\right) N_{\mathrm{PB}, \tau_{\mathrm{PB}, z}} \\
& e^{-\gamma_{\mathrm{PB}, z} \tau_{\mathrm{PB}, z}} \\
& +k_{\mathrm{N}, \mathrm{BM} 2 \mathrm{~PB}, z} N_{\mathrm{BM}}-k_{\mathrm{N}, \mathrm{PB} 2 \mathrm{LN}, z} N_{\mathrm{PB}} \\
\frac{d P_{\mathrm{PB}}}{d t}= & -\gamma_{\mathrm{PB}, z} P_{\mathrm{PB}}+\beta_{\mathrm{PB}}\left(N_{\mathrm{PB}}\right) N_{\mathrm{PB}} \\
& -\beta_{\mathrm{PB}}\left(N_{\mathrm{PB}, \tau_{\mathrm{PB}, z}}\right) N_{\mathrm{PB}, \tau_{\mathrm{PB}, z}} \\
& e^{-\gamma_{\mathrm{PB}, z} \tau_{\mathrm{PB}, z}} \\
& +k_{\mathrm{P}, \mathrm{BM} 2 \mathrm{~PB}, z} P_{\mathrm{BM}}-k_{\mathrm{P}, \mathrm{PB} 2 \mathrm{LN}, z} P_{\mathrm{PB}}
\end{aligned}
$$

\begin{tabular}{|c|c|c|}
\hline Parameter & Experimental Method & Source \\
\hline \multicolumn{3}{|c|}{ Experiments in Common Clinical Practice } \\
\hline $\mathrm{d}_{\mathrm{LN}, \mathrm{CLL}}$ & Ultrasound; CT scan & {$[7]$} \\
\hline $\mathrm{d}_{\mathrm{S}}, \mathrm{CLL}$ & CT scan & [7] \\
\hline $1_{S, C L L}$ & CT scan & [7] \\
\hline $\mathrm{V}_{\mathrm{CLL}, \mathrm{LN}}$ & Ultrasound & Est. \\
\hline $\mathrm{V}_{\mathrm{CLL}, \mathrm{S}}$ & CT scan or from enlarged dimensions & [7] \\
\hline $\mathrm{Nu}_{\mathrm{LN}}, d_{\mathrm{LN}}$, & CT scan & [7] \\
\hline $\mathrm{Ki}-67$ & Flow cytometry & [26] \\
\hline$\% \mathrm{BM}$ & Bone marrow biopsy & {$[28]$} \\
\hline \multicolumn{3}{|c|}{ Other Possible Experiments } \\
\hline$\tau$ & Response to PHA & [29] \\
\hline$\delta, \gamma$ & In vivo: Labelled ${ }^{2} \mathrm{H}_{2} \mathrm{O} ;$ Ex vivo: Trypan & {$[30,31]$} \\
\hline & blue, PI staining and Noxa expression & {$[32,33]$} \\
\hline \multicolumn{3}{|c|}{ Calculating Initial Conditions } \\
\hline$N_{\mathrm{BM}}, P_{\mathrm{BM}}$ & \multicolumn{2}{|l|}{$\% \mathrm{Ki}-67_{\mathrm{BM}}$ and $\% \mathrm{BM}$ in $\mathrm{Eq} 5$} \\
\hline$N_{\mathrm{PB}}, P_{\mathrm{PB}}$ & \multicolumn{2}{|l|}{$\% \mathrm{Ki}-67_{\mathrm{PB}}$ and blood tests } \\
\hline$N_{\mathrm{LN}}, P_{\mathrm{LN}}$ & \multicolumn{2}{|c|}{$\% \mathrm{Ki}-67_{\mathrm{LN}}$ and LN / S measurements by CT scan } \\
\hline
\end{tabular}

LN Eqs (11) \& (12) hold $\forall z \in\{$ SN, SA, SB, SC $\}$ :

$$
\begin{aligned}
\frac{d N_{\mathrm{LN}}}{d t}= & -\delta_{\mathrm{LN}, z} N_{\mathrm{LN}}-\beta_{\mathrm{LN}}\left(N_{\mathrm{LN}}\right) N_{\mathrm{LN}} \\
& +2 \beta_{\mathrm{LN}}\left(N_{\left.\mathrm{LN}, \tau_{\mathrm{LN}, z}\right) N_{\mathrm{LN}, \tau_{\mathrm{LN}}}} e^{-\gamma_{\mathrm{LN}, z} \tau_{\mathrm{LN}, z}+k_{\mathrm{N}, \mathrm{PB} 2 \mathrm{LN}, z} N_{\mathrm{PB}}}\right. \\
\frac{d P_{\mathrm{LN}}}{d t}=- & \gamma_{\mathrm{LN}, z} P_{\mathrm{LN}}+\beta_{\mathrm{LN}}\left(N_{\mathrm{LN}}\right) N_{\mathrm{LN}} \\
& -\beta_{\mathrm{LN}}\left(N_{\left.\mathrm{LN}, \tau_{\mathrm{LN}, z}\right)} N_{\mathrm{LN}, \tau_{\mathrm{LN}, z}}\right. \\
& e^{-\gamma_{\mathrm{LN}, z} \tau_{\mathrm{LN}, z}+k_{\mathrm{P}, \mathrm{PB} 2 \mathrm{LN}, z} P_{\mathrm{PB}}}
\end{aligned}
$$

\section{B. Algorithm for Determining Cell Cycle Parameters}

The model is an index-1 system with 6 differential and 23 algebraic equations, 76 parameters (22 assumed,
TABLE 3: Data sources for determining input parameters

38 calculated, 10 measured, 6 initial conditions), 6 state variables and 33 variables. Table 7 defines the symbols. Table 1 outlines PB lymphocyte doubling time (LDT) and clinical staging [19]. The 3 parameter types are:

(a) Assumed parameters from average human physiology or mathematical analysis - these parameters would be typically clinically unavailable,

(b) Measured parameters may be directly determined Table 3 proposes experimental methods and Table 7 lists typical values. Note that some measurements, e.g., from $\mathrm{PB}$, may be taken more frequently than from others, such as BM or LN,

(c) Calculated parameters that are deduced indirectly this section proposes a relevant algorithm.

Fig. 3 is an example of patient data trajectory within a disease stage. Transition time, or CLL stage duration $\Delta t_{z}=t_{\text {fin, } z}-t_{\text {in, } z}$, is estimated by treating physicians based on changes in PB LDT, increased lymphadenopathy or splenomegaly and low levels of hemoglobin or platelets. Appendices D - E describe an algorithm we developed in GAMS and MATLAB which finds values of $\theta_{i, 1, z}, \theta_{i, 2, z}, \delta_{i, z}, \gamma_{i, z}$ and $k_{\mathrm{N}, \mathrm{BM} 2 \mathrm{~PB}, z}, k_{\mathrm{P}, \mathrm{BM} 2 \mathrm{~PB}, z}$, $k_{\mathrm{N}, \mathrm{PB} 2 \mathrm{LN}, z}, k_{\mathrm{P}, \mathrm{PB} 2 \mathrm{LN}, z}, \forall i \in\{\mathrm{BM}, \mathrm{PB}, \mathrm{LN}\}$ and $\forall z \in$ $\{\mathrm{SN}, \mathrm{SA}, \mathrm{SB}, \mathrm{SC}\}$; this algorithm takes the measurable parameters and deduces reasonable values for the calculated parameters. We seek reasonable parameters rather than guaranteed parameter estimates of the best possible values; our purpose is to capture disease dynamics. We define reasonable parameters as satisfying the Table 1 disease characteristics and the Table 7 Source column; further model building could augment these restrictions.

\section{Global Sensitivity Analysis}

We apply random sampling - high dimensional model representation (RS-HDMR; Appendix F) global sensitivity analysis $[35,36]$ to the nominal parameter values. The minimum and maximum values of parameters included in Table 4 are used as inputs to the RS-HDMR model analysis (Table F.1 in Appendix F). The RS-HDMR 
TABLE 4: Cell cycle calculated and assumed parameters for the 5 hypothetical patients (P1 - P5)

\begin{tabular}{|c|c|c|c|c|c|c|c|c|c|c|c|c|}
\hline & & & \multicolumn{2}{|c|}{ P1 } & \multicolumn{2}{|c|}{$\mathbf{P 2}$} & \multicolumn{2}{|c|}{ P3 } & \multicolumn{2}{|c|}{ P4 } & \multicolumn{2}{|c|}{ P5 } \\
\hline & & & Initial & $\overline{\text { Final }}$ & Initial & $\overline{\text { Final }}$ & Initial & $\overline{\text { Final }}$ & Initial & Final & Initial & $\overline{\text { Final }}$ \\
\hline \multicolumn{3}{|c|}{ Transitions } & Naïve & A & A & B & A & B & B & $\mathrm{C}$ & A & $\mathrm{C}$ \\
\hline Calculated & $\gamma_{\mathrm{BM}}^{\dagger}$ & 1/day & 0.774 & 0.774 & 0.823 & 0.091 & 0.780 & 0.720 & 0.252 & 0.810 & 0.655 & 0.094 \\
\hline Parameters & $\gamma_{\mathrm{LN}}^{\dagger}$ & 1/day & 0.861 & 0.861 & 0.861 & 0.860 & 0.841 & 0.866 & 0.586 & 0.629 & 0.530 & 0.847 \\
\hline & $\gamma_{\mathrm{PB}}$ & $1 /$ day & 0.001 & 0.001 & 0.001 & 0.003 & 0.001 & 0.006 & 0.001 & 0.001 & 0.001 & 0.006 \\
\hline & $\delta_{\mathrm{BM}}$ & $1 /$ day & 0.001 & 0.001 & 0.001 & 0.034 & 0.001 & 0.001 & 0.001 & 0.001 & 0.001 & 0.037 \\
\hline & $\delta_{\mathrm{LN}}^{\dagger}$ & 1/day & 0.001 & 0.001 & 0.001 & 0.001 & 0.001 & 0.001 & 0.020 & 0.020 & 0.020 & 0.001 \\
\hline & $\delta_{\mathrm{PB}}$ & 1/day & 0.001 & 0.001 & 0.001 & 0.003 & 0.001 & 0.001 & 0.001 & 0.001 & 0.001 & 0.001 \\
\hline & $\tau_{\mathrm{BM}}$ & day & \multicolumn{2}{|c|}{0.792} & \multicolumn{2}{|c|}{0.792} & \multicolumn{2}{|c|}{0.792} & \multicolumn{2}{|c|}{0.625} & \multicolumn{2}{|c|}{0.792} \\
\hline & $\tau_{\mathrm{LN}}$ & day & \multicolumn{2}{|c|}{0.792} & \multicolumn{2}{|c|}{0.792} & \multicolumn{2}{|c|}{0.792} & \multicolumn{2}{|c|}{0.792} & \multicolumn{2}{|c|}{0.792} \\
\hline & $\tau_{\mathrm{PB}}$ & day & \multicolumn{2}{|c|}{0.792} & \multicolumn{2}{|c|}{0.625} & \multicolumn{2}{|c|}{0.625} & \multicolumn{2}{|c|}{0.625} & \multicolumn{2}{|c|}{0.625} \\
\hline & $\theta_{\mathrm{BM}, 1}^{\dagger}$ & $\cdot 10^{8}$ cells & 0.008 & 0.029 & 0.057 & 0.481 & 0.278 & 0.693 & 0.558 & 3.145 & 0.004 & 6.209 \\
\hline & $\theta_{\mathrm{BM}, 2}$ & $\cdot 10^{8}$ cells & 91.987 & 100.082 & 173.649 & 258.275 & 172.191 & 273.513 & 280.398 & 485.678 & 80.412 & 117.593 \\
\hline & $\theta_{\mathrm{LN}, 1^{\dagger}}^{\dagger}$ & $\cdot 10^{8}$ cells & 0.265 & 0.372 & 0.154 & 0.451 & 1.134 & 1.223 & 10.811 & 19.297 & 1.120 & 5.160 \\
\hline & $\theta_{\mathrm{LN}, 2}$ & $\cdot 10^{8}$ cells & 0.001 & 265.039 & 329.114 & 607.436 & 327.621 & 745.614 & 303.030 & 4788.246 & 281.928 & 714.329 \\
\hline & $\theta_{\mathrm{PB}, 1}$ & $\cdot 10^{8}$ cells & 0.001 & 0.008 & 0.007 & 0.104 & 0.063 & 0.132 & 0.677 & 1.259 & 0.018 & 0.224 \\
\hline & $\theta_{\mathrm{PB}, 2}$ & $\cdot 10^{8}$ cells & 15.000 & 16.450 & 20.000 & 33.050 & 20.000 & 43.100 & 210.000 & 457.000 & 45.000 & 51.450 \\
\hline & $k_{\mathrm{N}, \mathrm{BM} 2 \mathrm{~PB}}^{\dagger}$ & 1/day & 0.003 & 0.003 & 0.001 & 0.004 & 0.002 & 0.005 & 0.035 & 0.011 & 0.005 & 0.001 \\
\hline & $k_{\mathrm{P}, \mathrm{BM} 2 \mathrm{~PB}}^{\dagger}$ & $1 /$ day & 0.003 & 0.001 & 0.001 & 0.001 & 0.001 & 0.001 & 0.003 & 0.001 & 0.001 & 0.001 \\
\hline & $k_{\mathrm{N}}, \mathrm{PB} 2 \mathrm{LN}{ }^{\dagger}$ & $1 /$ day & 0.003 & 0.002 & 0.001 & 0.001 & 0.001 & 0.003 & 0.005 & 0.001 & 0.001 & 0.001 \\
\hline & $k_{\mathrm{P}, \mathrm{PB} 2 \mathrm{LN}}^{\dagger}$ & $1 /$ day & 0.033 & 0.007 & 0.013 & 0.007 & 0.008 & 0.006 & 0.001 & 0.001 & 0.001 & 0.014 \\
\hline Assumed & $t_{\text {in }}$ & day & 0 & 1000 & 0 & 1800 & 0 & 365 & 0 & 365 & 0 & 365 \\
\hline Parameters & $t_{\text {fin }}$ & day & 1000 & 3190 & 1800 & 2165 & 365 & 730 & 365 & 730 & 365 & 730 \\
\hline
\end{tabular}

TABLE 5: Initial characteristics of the 5 hypothetical patients (more details in Appendix Table E.1)

\begin{tabular}{lccccccc}
\hline Patient & P1 & P2 & P3 & P4 & P5 & CLL \\
\hline Bone Marrow Infiltration & $37.3 \%$ & $46.7 \%$ & $46.7 \%$ & $52.1 \%$ & $37.4 \%$ & & \\
\cline { 2 - 7 } CLL in PB (cells/ $\mu \mathrm{L}$ ) & 6018 & 8016 & 8016 & 84168 & 18040 & $\geq 5000$ for at & {$[10]$} \\
LN \& S (cells) & 0 & $1340 \cdot 10^{8}$ & $1340 \cdot 10^{8}$ & $1326 \cdot 10^{8}$ & $1047 \cdot 10^{8}$ & least 3 months $^{\dagger}$ & \\
\cline { 2 - 8 } Ki-67 \% in PB & $0.30 \%$ & $0.20 \%$ & $0.20 \%$ & $0.20 \%$ & $0.22 \%$ & $0.36 \pm 0.34 \% \ddagger$ & {$[26]$} \\
LN \& S & $0.00 \%$ & $2.99 \%$ & $2.99 \%$ & $2.00 \%$ & $4.50 \%$ & $4.95 \pm 0.55 \% \ddagger$ & {$[26]$} \\
BM & $2.70 \%$ & $1.95 \%$ & $1.95 \%$ & $3.00 \%$ & $1.76 \%$ & $2.48 \pm 0.77 \% \ddagger$ & {$[26]$} \\
\hline Expected LDT (months) & $\infty \rightarrow 60$ & $60 \rightarrow 12$ & $12 \rightarrow 12$ & $12 \rightarrow<12$ & $60 \rightarrow<12$ & & {$[19]$} \\
\hline
\end{tabular}

${ }^{\dagger}$ Values for CLL published by the World Health Organization, ${ }^{\ddagger}$ Average values of Ki-67 in tissues

output variables are the number of proliferative and nonproliferative CLL cells in BM, PB and LN including S.

$$
\text { 3. CASE STUdies }
$$

The initial characteristics of 5 hypothetical patients (P1 - P5) are posited in Table 5. The 5 hypothetical patients represent a range of clinically-relevant physiological conditions (disease heterogeneity) based on common disease presentation (Table 1 and Appendices $\mathrm{C}-\mathrm{G})$. The only exception is $\mathrm{P} 3$ which represents the model outcome described by Molica et al. [37] where a patient in Binet Stage A has a lymphocyte doubling time, LDT $\leq 12$ months (Appendix E). The 5 hypothetical patient trajectories (P1 - P5) we model are:

- P1: Naïve Stage (LDT: $\infty) \rightarrow$ Binet Stage A (LDT $=60$ months)

- P2: Binet Stage A (LDT $=60$ months) $\rightarrow$ Binet Stage B (LDT $=12$ months)

- P3: Binet Stage A (LDT $=12$ months) $\rightarrow$ Binet Stage B (LDT = 12 months)
- P4: Binet Stage B (LDT $=12$ months $) \rightarrow$ Binet Stage C (LDT $=12$ months)

- P5: Binet Stage A (LDT $=60$ months) $\rightarrow$ Binet Stage C (LDT $=7$ months)

We also make the following assumptions: (a) normal lymphocyte count in each tissue is stable, (b) zero net migration of normal lymphocytes, (c) normal bone marrow lymphocytes have percentage $a_{\mathrm{BM}}=25 \%$ [38], (d) peripheral blood volume is $5 \mathrm{~L}$ [39], (e) the maximum recruitment rate $\beta_{N, 0}$ equals 3.35 /day in each tissue [25]; (f) CLL disease stage duration, $\Delta t_{z}$, is based on LDT (Table 1) and has values [days]: 1000, 1800, 365, 365 and 365 for the 5 case studies, P1 - P5, respectively.

We apply the Section 2.B algorithm for determining parameters to the 5 case studies, simulate the trajectories of Eq (1) - (12) and predict future patient signs/sequelae via correlation with the simulated CLL cells number in each disease center. For more detail, 


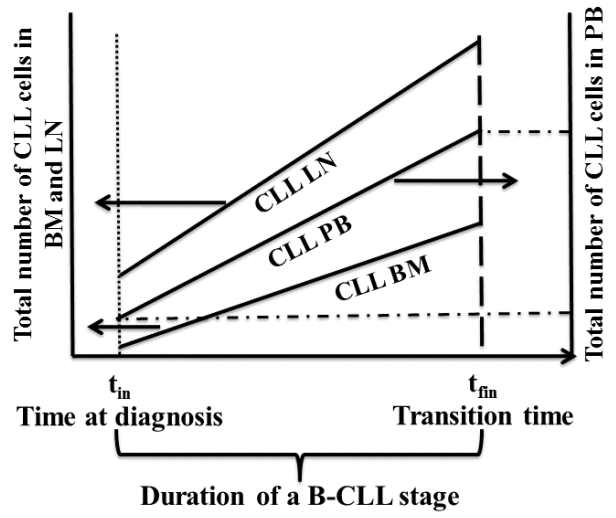

Fig. 3: Example patient trajectory within a disease stage; horizontal lines show PB LDT calculation and vertical lines show transition from initial diagnosis at time $t_{\text {in }}$ to the point of progression to a new phase at $t_{\text {fin }}$

see Appendix D. We consider 4 types of physical signs: (a) high infiltration pattern of BM predicted from Eq (5), (b) only splenomegaly, (c) only lymphadenopathy, and (d) combined splenomegaly and lymphadenopathy (Appendices $\mathrm{C}$ and $\mathrm{G}$ ). We implemented the model in MATLAB R2013a (8.1.0.604) and GAMS 24.1.3 (solver: CONOPT) on a $4.40 \mathrm{GHz}$ Intel Core i7-4770 processor with 8GB RAM running 64-bit Windows 7; each simulation took $0.1-0.2$ CPU s.

\section{RESUlts AND Discussion}

Results are in Tables $4 \& 6$ and Fig. 4. The clinical predictions in Table 6 are based on analyses in Appendices $\mathrm{C}$ and $\mathrm{G}$; Fig. 4 diagrams the MATLAB outputs. The sequel comments on each of the 5 case studies.

P1 starts from a naïve stage with high LDT and progresses to Binet Stage A (LDT 60 months); the proliferation increase of $\approx 33$ months after initial diagnosis correlates with the increased recruitment rates into the bonemarrow and lymph node cell cycles. P2 and P3 have similar initial disease characteristics (\% CLL cells in bone marrow and \% Ki-67) but diverge with respect to initial LDT; these two test cases correspond to work showing that LDT significantly impacts the probability of progression from Binet Stage A to B within a year [37]. The model captures this progression tempo; $\mathrm{P} 2$ and $\mathrm{P} 3$ progress to Stage B in 60 and 12 months, respectively.

P4 shows a trajectory from Binet Stage B to C where the bone marrow pattern changes from mixed to diffuse and the rate of lymphocyte doubling is roughly constant at 12 months; the fraction of CLL cells migrating decreased or remained stable in the $\mathrm{P} 4$ trajectory. Note here that, although the definition of Binet Stage $\mathrm{C}$ requires a descriptor of anemia and low platelets (Table 1), we use instead an indirect metric, assuming that the signs of Binet Stage C will follow from an increase in bone marrow tumor burden. Finally, P5 is an unusual CLL case; the disease initiates slowly in Binet Stage A and bone marrow failure occurs quickly within 2 years.

RS-HDMR analysis of the CLL model in Binet Stages from A to C, illustrated in Fig. F.2 of Appendix F for 5000 HDMR samples is done in Matlab with dde23 solver. The parameters $\left(S_{i} \geq 0.1\right)$ of this model which most significantly affect disease trajectory over space and time are: (i) the initial number of CLL cells in peripheral blood, the number of involved (enlarged) lymph nodes and the presence and degree of splenomegaly, (ii) the migratory fractions of non-proliferating as well as proliferating CLL cells from bone marrow into peripheral blood and of proliferating CLL cells from peripheral blood to lymph nodes and, (iii) the parameter inducing non-proliferative cells to proliferate. Several critical parameters identified by our model (enlarged lymph nodes, splenomegaly, LDT) are already used in staging systems, but none of: (i) total CLL cell number, (ii) migration rate and, (iii) propensity to induce proliferation (unless directly incurred by a known mutation, e.g., p53, or mutated pathway) is currently used. We therefore propose these factors for inclusion in multi-parameter models of disease progression, as targets for prevention of progression or therapy. In particular, the use of migration rate, e.g., using chemokine or integrin surface markers or other relevant serum biomarkers, and the induction of a cell proliferation profile, e.g., via mutated cell cycle checkpoints or intracellular pathways such as PI3K, could be important focal points for inclusion in future research. These parameters could be made readily available for input into models on a patient-specific basis over the disease course from peripheral blood tests done at the bedside (for migration assessments) and from sampling of the primary disease center, e.g., lymph node or bone marrow for proliferation parameters via fine needle aspirate or core biopsy - both routine procedures.

Expression of Ki-67, a proliferation marker found in cycle phases G1, S, G2, and M but not G0 [40], is found in tissues affected by CLL in varying percentage: peripheral blood $0.36 \pm 0.34 \%$, bone marrow $2.48 \pm 0.77 \%$, and lymph nodes and spleen $4.95 \pm 0.55 \%$ [26]. In addition to having higher proliferative features than those of bone marrow or peripheral blood, lymph nodes and spleen disease centers in CLL also have lower death rates [33, 34], a feature which has been partially attributed to the microenvironment [41]. One of the earliest mathematical frameworks of CLL models the interaction between CLL cells and T-cells, a component of the microenvironment, via a Volterra predator-prey equation [42]. A kinetic model [30] has also been used to develop the first model of CLL incorporating interactions between CLL cells, natural killer (NK) cells, cytotoxic (CD8+) T-cells and helper (CD4+) T-cells [43]. This model implicitly as- 

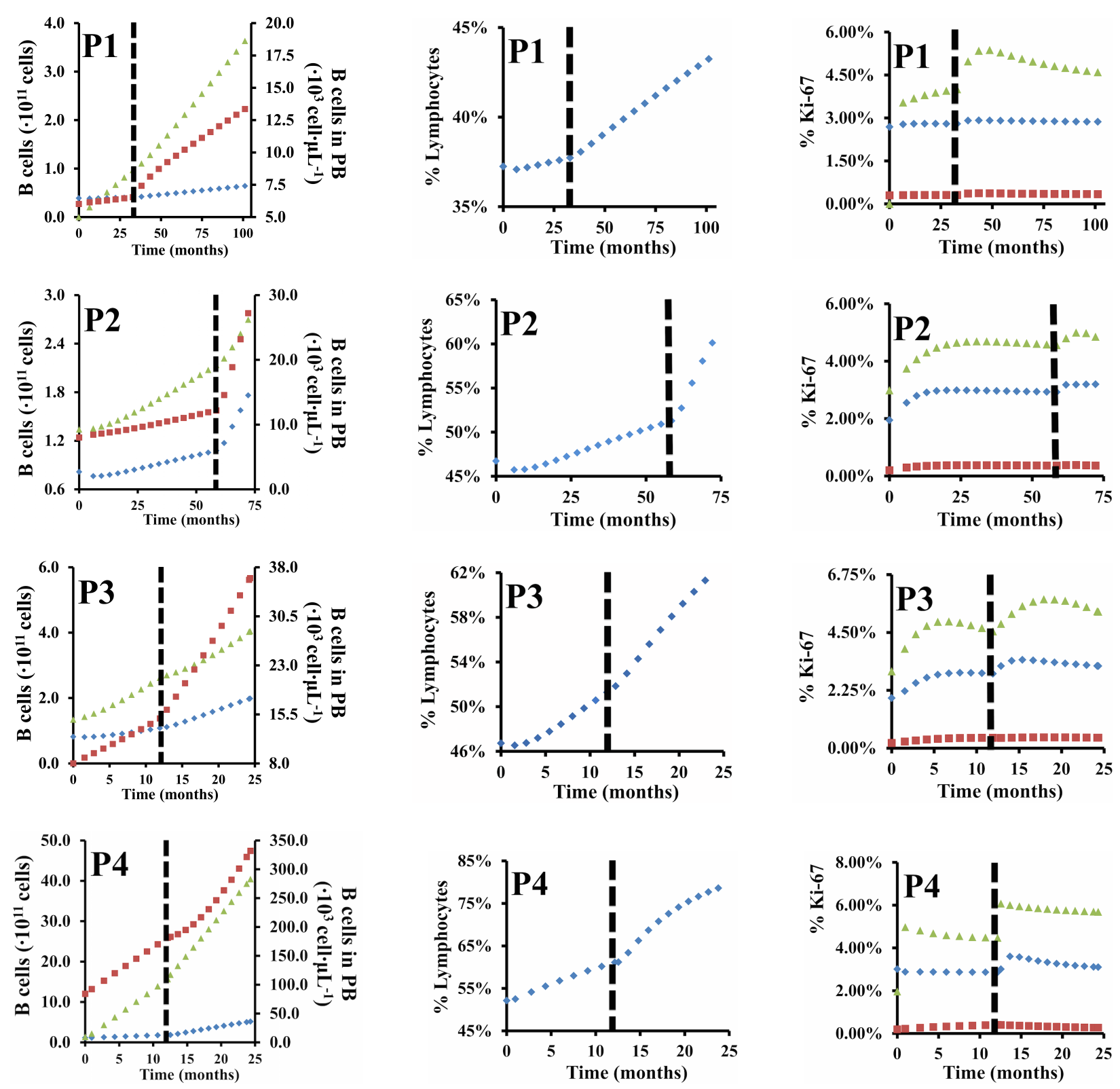

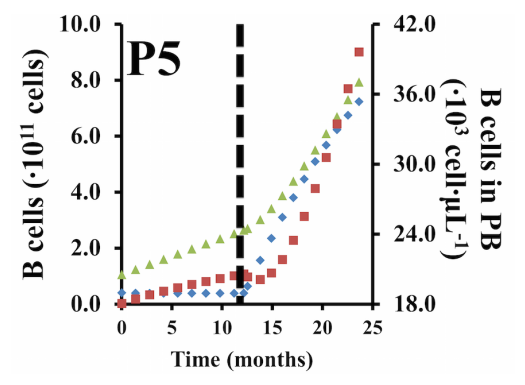

(a) Lymphocytes in organs

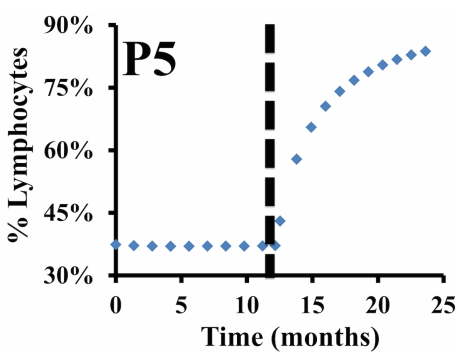

(b) Bone marrow infiltration pattern

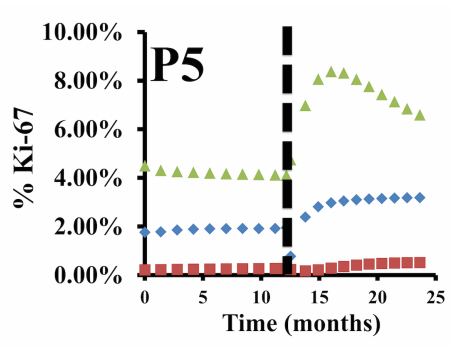

(c) Ki-67 in organs

$\diamond \mathrm{BM} \approx \mathrm{PB} \triangle \mathrm{LN} \& \mathrm{~S}$

Fig. 4: Characteristics of CLL in theoretical patients P1 - P5. Each row represents one patient; the vertical dashed lines represent transitions between disease stages 
TABLE 6: Possible characteristics of 5 hypothetical patients derived from the mathematical model

\begin{tabular}{|c|c|c|c|}
\hline & Symptoms & Initially & Finally \\
\hline $\begin{array}{l}\text { P1: Naïve } \rightarrow \text { Binet Stage } A \\
\text { LDT: } \infty \rightarrow 60 \text { months }\end{array}$ & $\begin{array}{l}\text { Bone marrow pattern } \\
\text { Enlarged lymph nodes } \\
\text { Splenomegaly }\end{array}$ & $\begin{array}{c}\text { Interstitial or nodular } \\
\text { No } \\
\text { No }\end{array}$ & $\begin{array}{c}\text { Interstitial or nodular } \\
\text { [Diameter }(\mathbf{c m}), \#][3,5],[4,2],[5,1] \\
\text { No }\end{array}$ \\
\hline $\begin{array}{l}\text { P2: Binet Stage } A \rightarrow B \\
\text { LDT: } 60 \text { months } \rightarrow 12 \text { months }\end{array}$ & $\begin{array}{l}\text { Bone marrow pattern } \\
\text { Enlarged lymph nodes } \\
\text { Splenomegaly }\end{array}$ & $\begin{array}{c}\text { Interstitial or nodular } \\
\text { Yes } \\
\text { No }\end{array}$ & $\begin{array}{c}\text { Mixed } \\
\text { [Diameter }(\mathbf{c m}), \#][3,2],[4,1] \\
\text { Mild to moderate }(5 \times 12 \mathrm{~cm})\end{array}$ \\
\hline $\begin{array}{l}\text { P3: Binet Stage } A \rightarrow B \\
\text { LDT: } 12 \text { months } \rightarrow 12 \text { months }\end{array}$ & $\begin{array}{l}\text { Bone marrow pattern } \\
\text { Enlarged lymph nodes } \\
\text { Splenomegaly }\end{array}$ & $\begin{array}{c}\text { Interstitial or nodular } \\
\text { Yes } \\
\text { No }\end{array}$ & $\begin{array}{c}\text { Mixed } \\
\text { [Diameter }(\mathbf{c m}), \#][3,4],[4,2] \\
\text { Mild to moderate }(5 \times 12 \mathrm{~cm})\end{array}$ \\
\hline $\begin{array}{l}\text { P4: Binet Stage } B \rightarrow C \\
\text { LDT: } 12 \text { months } \rightarrow 12 \text { months }\end{array}$ & $\begin{array}{l}\text { Bone marrow pattern } \\
\text { Enlarged lymph nodes } \\
\text { Splenomegaly }\end{array}$ & $\begin{array}{l}\text { Mixed } \\
\text { Yes } \\
\text { No }\end{array}$ & $\begin{array}{c}\text { Diffuse } \\
\text { [Diameter }(\mathbf{c m}), \#][4,11],[5,6],[6,5] \\
\text { Marked }(7 \times 14 \mathrm{~cm})\end{array}$ \\
\hline $\begin{array}{l}\text { P5: Binet Stage } A \rightarrow C \\
\text { LDT: } 60 \text { months } \rightarrow 7 \text { months }\end{array}$ & $\begin{array}{l}\text { Bone marrow pattern } \\
\text { Enlarged lymph nodes } \\
\text { Splenomegaly }\end{array}$ & $\begin{array}{c}\text { Interstitial or Nodular } \\
\text { No } \\
\text { No }\end{array}$ & $\begin{array}{c}\text { Diffuse } \\
\text { [Diameter }(\mathbf{c m}), \#][3,5],[4,2] \\
\text { Mild to moderate }(5 \times 15 \mathrm{~cm})\end{array}$ \\
\hline
\end{tabular}

sumes that the entire body is 1-compartment and thereby does not account for the proliferation center microenvironment, disease center carrying capacity, or the cellular migration between disease centers [43]. CLL lymphocytosis kinetics have been studied using a 2-compartment model [30] that characterizes CLL cell redistribution dynamics from proliferation centers into the peripheral blood induced by the novel BTK inhibitor, Ibrutinib albeit there is little known about steady-state dynamics or of that which occurs during the natural course of disease [44]. Variations may assume different cell cycle models for each disease compartment. For example, immunophenotyping to distinguish between B- and Tcells in the peripheral blood lymphocyte compartment $[41,45]$ which may facilitate the incorporation of immune interactions and current immuno-chemotherapeutic targets [46]. Our model therefore complements the 1compartment model of Nanda et al. [43]. If we could assume data on T-cell populations, i.e., CD4+, CD8+, the Nanda et al. [43] model could replace each G0 model in Fig. 1. This manuscript does not use the optional T-cell module and reflects data availability from typical clinical protocols with first-order approximation that $90 \%$ of lymphocytes in affected tissues are CLL cells [41].

Our model meaningfully adapts to each of the disparate case studies and the parameters and variables adhere to physiologically-relevant values. The proposed framework has been developed using a variety of hypothetical test cases. However, used in tandem with real patient data and other clinical diagnostic tools [47, 48], the developed algorithm may enable patientspecific, leukemia-specific disease dynamic modeling for actual patients with CLL. It also provides insight into the trajectory of disease progression and presents CLL cell migration and propensity towards proliferation as avenues of future research.

\section{CONCLUSIONS}

This paper develops the first physiologically-relevant mathematical model of CLL connecting the most af- fected tissues. The mathematical novelty stems from the integration of both temporal and spatial CLL aspects. The delay differential equations incorporate the temporal aspect of cell division. The model is practical in that (1) measurable input parameters have been taken from common clinical protocols, (2) from data which is readily accessible in current standard clinical practice, (3) it captures physiologically-relevant transitions from Binet Stage A to C and, (4) it predicts outcomes which may be clinically useful for expectant patient care if validated using primary patient data. Using the model, we found that CLL cell migration between disease centers and the induction of CLL cells into proliferative phase are critical parameters determining disease evolution and should be evaluated in future research.

\section{REFERENCES}

[1] K. N. Potter et al., "Features of the overexpressed v1-69 genes in the unmutated subset of chronic lymphocytic leukemia are distinct from those in the healthy elderly repertoire," Blood, vol. 101, no. 8, pp. 3082-3084, 2003.

[2] X. S. Puente and C. López-Otín, "The evolutionary biography of chronic lymphocytic leukemia," Nat Genet, vol. 45, no. 3, pp. 229-231, 2013.

[3] S. López-Giral et al., "Chemokine receptors that mediate B cell homing to secondary lymphoid tissues are highly expressed in B cell chronic lymphocytic leukemia and non-Hodgkin lymphomas with widespread nodular dissemination," J Leukoc Biol, vol. 76, no. 2, pp. 462-471, 2004.

[4] T. N. Hartmann et al., "Circulating B-cell chronic lymphocytic leukemia cells display impaired migration to lymph nodes and bone marrow," Cancer Res, vol. 69, no. 7, pp. 3121-3130, 2009.

[5] C. Scielzo et al., "HS1 has a central role in the trafficking and homing of leukemic B cells," Blood, vol. 116, pp. 3537-3546, 2010.

[6] D. Galton, "The pathogenesis of chronic lymphocytic leukemia," Can Med Assoc J, vol. 94, no. 19, p. 1005, 1966.

[7] C. C. Mo et al., "Rapid clearance of rituximab may contribute to the continued high incidence of autoimmune hematologic complications of chemoimmunotherapy for chronic lymphocytic leukemia," Haematologica, vol. 98, no. 8, pp. 1259-1263, 2013.

[8] J.-L. Binet et al., "Chronic Lymphocytic Leukaemia: Proposals for a Revised Prognostic Staging System," Br J Haematol, vol. 48, no. 3, pp. 365-367, 1981.

[9] J. Binet et al., "A new prognostic classification of chronic lymphocytic leukemia derived from a multivariate survival analysis," Cancer, vol. 48, no. 1, pp. 198-206, 1981. 
[10] S. Swerdlow et al., WHO Classification of Tumours of Haematopoietic and Lymphoid Tissues, ser. IARC WHO Classification of Tumours Series. International Agency for Research on Cancer, 2008, ch. 10.Mature B-cell Neoplasms, pp. 179-268.

[11] F. Caligaris-Cappio and T. J. Hamblin, "B-cell chronic lymphocytic leukemia: a bird of a different feather," J Clin Oncol, vol. 17, no. 1, pp. 399-399, 1999.

[12] E. Velliou et al., "A framework for the design, modeling and optimization of biomedical systems," in FOCAPD, ser. ComputerAided Chemical Engineering, vol. 34, 2014, pp. 225 - 236.

[13] E. Pefani et al., "Design of optimal patient-specific chemotherapy protocols for the treatment of acute myeloid leukemia (AML)," Comput Chem Eng, vol. 57, pp. 187-195, 2013.

[14] — "Chemotherapy drug scheduling for the induction treatment of patients with acute myeloid leukemia," IEEE Trans Biomed Eng, vol. 61, no. 7, pp. 2049-2056, 2014.

[15] P. Dua et al., "Multi-objective blood glucose control for type 1 diabetes," Med Biol Eng Comput, vol. 47, pp. 343-352, 2009.

[16] A. Krieger et al., "Modeling and analysis of individualized pharmacokinetics and pharmacodynamics for volatile anesthesia," IEEE Trans Biomed Eng, vol. 61, no. 1, pp. 25-34, 2014.

[17] I. Nascu et al., "Advanced model based control studies for the induction and maintenance of intravenous anaesthesia," IEEE Trans Biomed Eng, vol. 62, no. 3, pp. 832 - 841, 2015.

[18] S. Savvopoulos et al., "Global sensitivity analysis for a dynamic model of chronic lymphocytic leukemia disease trajectories," Computer Aided Chemical Engineering, 2015.

[19] E. Montserrat et al., "Lymphocyte doubling time in chronic lymphocytic leukaemia: analysis of its prognostic significance," Br J Haematol, vol. 62, no. 3, pp. 567-575, 1986.

[20] M. Hallek and on behalf of the German CLL Study Group, "Prognostic factors in chronic lymphocytic leukemia," Annals of Oncology, vol. 19, no. suppl 4, pp. iv51-iv53, 2008.

[21] F. Trepel, "Number and distribution of lymphocytes in man. a critical analysis," Klin Wochenschr, vol. 52, pp. 511-515, 1974.

[22] J. Westermann and R. Pabst, "Distribution of lymphocyte subsets and natural killer cells in the human body," The Clinical Investigator, vol. 70, no. 7, pp. 539-544, 1992.

[23] M. C. Mackey, "Unified hypothesis for the origin of aplastic anemia and periodic hematopoiesis," Blood, vol. 51, pp. 941956, 1978.

[24] M. Fuentes-Garí et al., "A mathematical model of subpopulation kinetics for the deconvolution of leukaemia heterogeneity," $J R$ Soc Interface, vol. 12, no. 108, 2015.

[25] L. K. Andersen and M. C. Mackey, "Resonance in periodic chemotherapy: a case study of acute myelogenous leukemia," $J$ Theor Bio, vol. 209, no. 1, pp. 113-130, 2001.

[26] O. Khoudoleeva et al., "Proliferative index and expression of CD38, ZAP-70, and CD25 in different lymphoid compartments of chronic lymphocytic leukemia patients," Pathol Lab Med, vol. 3, pp. 7-16, 2011.

[27] A. L. MacLean et al., "The ecology in the hematopoietic stem cell niche determines the clinical outcome in chronic myeloid leukemia," PNAS USA, vol. 111, pp. 3883-3888, 2014.

[28] C. Rozman et al., "Bone marrow histologic pattern-the best single prognostic parameter in chronic lymphocytic leukemia: a multivariate survival analysis of 329 cases," Blood, vol. 64, no. 3 , pp. 642-648, 1984.

[29] L. I. Johnson et al., "The lymphocytes of chronic lymphocytic leukemia: their proliferation and cell cycle kinetics," Cell Prolif, vol. 5, no. 1, pp. 27-34, 1972.

[30] B. T. Messmer et al., "In vivo measurements document the dynamic cellular kinetics of chronic lymphocytic leukemia B cells," J Clin Invest, vol. 115, no. 3, pp. 755-764, 2005.

[31] R. van Gent et al., "In vivo dynamics of stable chronic lymphocytic leukemia inversely correlate with somatic hypermutation levels and suggest no major leukemic turnover in bone marrow," Cancer Res, vol. 68, no. 24, pp. 10 137-10 144, 2008.

[32] L. Lagneaux et al., "Chronic lymphocytic leukemic B cells but not normal B cells are rescued from apoptosis by contact with normal bone marrow stromal cells," Blood, vol. 91, no. 7, pp. 2387-2396, 1998.

[33] L. A. Smit et al., "Differential Noxa/Mcl-1 balance in peripheral versus lymph node chronic lymphocytic leukemia cells correlates with survival capacity," Blood, vol. 109, pp. 1660-1668, 2007.

[34] Y. Herishanu et al., "The lymph node microenvironment promotes B-cell receptor signaling, NF- $\kappa \mathrm{B}$ activation, and tumor proliferation in chronic lymphocytic leukemia," Blood, vol. 117, no. 2, pp. 563-574, 2011.

[35] A. Kiparissides et al., "Global sensitivity analysis challenges in biological systems modeling," Ind Eng Chem Res, vol. 48, no. 15, pp. 7168-7180, 2009.

[36] G. Li et al., "Practical approaches to construct RS-HDMR component functions," J Phys Chem A, vol. 106, no. 37, pp. 8721-8733, 2002.

[37] S. Molica and A. Alberti, "Prognostic value of the lymphocyte doubling time in chronic lymphocytic leukemia," Cancer, vol. 60, no. 11 , pp. 2712-2716, 1987.

[38] P. Clark et al., "Lymphocyte subsets in normal bone marrow," Blood, vol. 67, no. 6, pp. 1600-1606, 1986.

[39] P. Russell et al., Biology: The Dynamic Science. Brooks/Cole CENGAGE Learning, 2010, ch. The Circulatory System, pp. 953-973.

[40] J. Gerdes et al., "Cell cycle analysis of a cell proliferationassociated human nuclear antigen defined by the monoclonal antibody Ki-67," J Immunol, vol. 133, pp. 1710-1715, 1984.

[41] L. Granziero et al., "Survivin is expressed on CD40 stimulation and interfaces proliferation and apoptosis in B-cell chronic lymphocytic leukemia," Blood, vol. 97, no. 9, pp. 2777-2783, 2001.

[42] B. Vitale, et al., "Prolegomenon for chronic lymphocytic leukaemia," Scand J Immunol, vol. 58, no. 6, pp. 588-600, 2003.

[43] S. Nanda et al., "B Cell Chronic Lymphocytic Leukemia-A Model with Immune Response," Discret Contin Dyn S B, vol. 18, no. 4, pp. 1053 - 1076, 2013.

[44] D. Wodarz et al., "Kinetics of CLL cells in tissues and blood during therapy with the BTK inhibitor ibrutinib," Blood, vol. 123, no. 26, pp. 4132-4135, 2014

[45] C. L. Goolsby et al., "Expansions of clonal and oligoclonal $\mathrm{T}$ cells in B-cell chronic lymphocytic leukemia are primarily restricted to the CD3+CD8+ T-cell population," Cytometry, vol. 42, no. 3, pp. 188-195, 2000.

[46] M. J. Keating et al., "Long-term follow-up of patients with chronic lymphocytic leukemia (CLL) receiving fludarabine regimens as initial therapy," Blood, vol. 92, pp. 1165-1171, 1998.

[47] J. M. Harrold and R. S. Parker, "Clinically relevant cancer chemotherapy dose scheduling via mixed-integer optimization," Comput Chem Eng, vol. 33, pp. 2042 - 2054, 2009.

[48] M. Heitzig et al., "A computer-aided framework for development, identification and management of physiologically-based pharmacokinetic models," Comput Chem Eng, vol. 71, pp. 677 - 698, 2014.

[49] M. K. Anand, Anand's Human Anatomy for Dental Students. JP Medical Ltd, 2011, ch. 33. Lymphoid Tissue and Joints of Head and Neck, pp. 443-448.

[50] A. J. Rodrigues et al., "Sonographic assessment of normal spleen volume," Clinical Anatomy, vol. 8, no. 4, pp. 252-255, 1995.

[51] R. Kuse et al., "Blood lymphocyte volumes and diameters in patients with chronic lymphocytic leukemia and normal controls," Blut, vol. 50, no. 4, pp. 243-248, 1985.

[52] M. Plander et al., "Different proliferative and survival capacity of cll-cells in a newly established in vitro model for pseudofollicles," Leukemia, vol. 23, no. 11, pp. 2118-2128, 2009.

[53] T. Ziehn and A. Tomlin, "Global sensitivity analysis of a 3D street canyon model-Part I: The development of high dimensional model representations," Atmos Environ, vol. 42, no. 8, pp. 1857-1873, 2008.

[54] G. Schmidt, Differential Diagnosis in Ultrasound Imaging: A Teaching Atlas. Thieme, 2011, ch. 5. Spleen, pp. 173-197.

[55] L. Weiss, Lymph Nodes. Cambridge University Press, 2008, ch. 2. Normal Lymph Node, pp. 5-13. 
TABLE 7: Symbol Definition

\begin{tabular}{|c|c|c|c|c|c|}
\hline & Symbol & Value & Units & Description & Source \\
\hline \multirow{4}{*}{ Indices } & \multicolumn{2}{|c|}{$\begin{array}{l}\text { CLL } \\
t \in\{\text { in, fin }\} \\
d \in\{\mathrm{LB}, \mathrm{AV}, \mathrm{UB}\}\end{array}$} & & \multicolumn{2}{|l|}{$\begin{array}{l}\text { B-Cell Chronic Lymphocytic Leukemia Cells } \\
\text { Time points } t \text {; in } \equiv \text { initial; fin } \equiv \text { final } \\
\text { Data } d: \mathrm{LB} \equiv \text { Lower Bound; } \mathrm{AV} \equiv \text { Average; UB } \equiv \text { Upper Bound }\end{array}$} \\
\hline & \multicolumn{3}{|c|}{$h \in\{\mathrm{BM} 2 \mathrm{~PB}, \mathrm{~PB} 2 \mathrm{LN}\}$} & \multicolumn{2}{|l|}{$\begin{array}{l}\text { Net flow } h \text { of CLL cells: BM2PB } \equiv \text { bone marrow } \rightarrow \text { peripheral blood; PB2LN } \equiv \\
\text { peripheral blood } \rightarrow \text { lymph nodes and spleen }\end{array}$} \\
\hline & \multicolumn{2}{|c|}{$i \in\{\mathrm{NC}, \mathrm{BM}, \mathrm{PB}, \mathrm{LN}, \mathrm{S}\}$} & & \multicolumn{2}{|c|}{$\begin{array}{l}\text { Cell types } i ; \mathrm{NC} \equiv \text { Normal lymphocyte in any tissue; } \mathrm{BM} \equiv \mathrm{CLL} \text { in bone marrow } \\
\text { (proliferating region); } \mathrm{PB} \equiv \mathrm{CLL} \text { in peripheral blood (non-proliferating region); LN } \\
\equiv \mathrm{CLL} \text { in lymph node (proliferating region); } \mathrm{S} \equiv \mathrm{CLL} \text { in spleen (proliferating } \\
\text { region, grouped with } \mathrm{LN} \text { in our analysis); LC } \equiv \text { lymphocytes }\end{array}$} \\
\hline & \multicolumn{3}{|c|}{$z \in\{\mathrm{SN}, \mathrm{SA}, \mathrm{SB}, \mathrm{SC}\}$} & \multicolumn{2}{|c|}{$\begin{array}{l}\text { Stage of the disease: } \mathrm{SN} \equiv \text { Naïve Stage; } \mathrm{SA} \equiv \text { Binet Stage } \mathrm{A} ; \mathrm{SB} \equiv \text { Binet Stage } \mathrm{B} \\
\mathrm{SC} \equiv \text { Binet Stage } \mathrm{C}\end{array}$} \\
\hline $\begin{array}{l}\text { State } \\
\text { Variables }\end{array}$ & $\begin{array}{l}\mathrm{P}_{i} \\
\mathrm{~N}_{i}\end{array}$ & & $\begin{array}{l}\text { cells } \\
\text { cells }\end{array}$ & $\begin{array}{l}\text { Proliferating cells in compartments } i \in\{\mathrm{NC}, \mathrm{BM}, \mathrm{PB}, \mathrm{LN}\} \\
\text { Non-proliferating cells in compartments } i \in\{\mathrm{NC}, \mathrm{BM}, \mathrm{PB}, \mathrm{LN}\}\end{array}$ & \\
\hline $\begin{array}{l}\text { Assumed } \\
\text { Parameters }\end{array}$ & $\begin{array}{l}a_{\mathrm{BM}} \\
\beta_{\mathrm{N}_{i}, 0} \\
\mathrm{~d}_{\mathrm{LN}, \mathrm{NC}} \\
\mathrm{d}_{\mathrm{S}, \mathrm{NC}} \\
\mathrm{l}_{\mathrm{S}, \mathrm{NC}} \\
\mathrm{n}_{i} \\
\mathrm{~V}_{\mathrm{LN}, \mathrm{NC}} \\
\mathrm{V}_{\mathrm{S}} \\
\mathrm{V}_{\mathrm{CLL}} \\
t_{\mathrm{in}, z} \\
t_{\mathrm{fin}, z} \\
\mathrm{C}_{\mathrm{NC}, \mathrm{BM}} \\
\mathrm{BM}_{\max } \\
\% \mathrm{Ki}-67_{i, \mathrm{AV}}\end{array}$ & $\begin{array}{l}24.7 \pm 9.7 \\
3.35 \\
{[1,2]} \\
5 \\
11 \\
3 \\
0.52 \\
215.86 \\
166 \times 10^{-12}\end{array}$ & $\begin{array}{l}\% \\
1 / \text { day } \\
\mathrm{cm} \\
\mathrm{cm} \\
\mathrm{cm} \\
- \\
\mathrm{cm}^{3} \\
\mathrm{~cm}^{3} \\
\mathrm{~cm}^{3} \\
\text { day } \\
\text { day } \\
\text { cells } \\
\text { cells } \\
\%\end{array}$ & $\begin{array}{l}\text { Percentage of lymphocytes in healthy bone marrow } \\
\text { Maximum recruitment rate } \\
\text { Normal lymph node diameter } \\
\text { Normal spleen diameter } \\
\text { Normal spleen length } \\
\text { Control shape of the Eq (D.7) feedback function } \\
\text { Normal lymph node volume } \\
\text { Normal spleen volume ( } 147.50 \pm 81.46) \\
\text { Volume of a CLL cell } \\
\text { Time when disease stage } z \text { starts } \\
\text { Time when disease stage } z \text { finishes } \\
\text { Normal number of lymphocytes in bone marrow } \\
\text { Maximum number of cells in bone marrow } \\
\text { Average Ki-67 of CLL in tissues. Ki-67 } \mathrm{BM}, \mathrm{AV}=2.48 \pm 0.77 \% \text {; } \\
\text { Ki-67 } \mathrm{PB}, \mathrm{AV}=0.36 \pm 0.34 \% \text { Ki- } 67_{\mathrm{LN}}, \mathrm{AV}=4.95 \pm 0.55 \% ;\end{array}$ & $\begin{array}{l}{[38]} \\
{[23,25]} \\
{[49]} \\
\text { Table G. } 1^{\dagger} \\
\text { Table G. } 1^{\dagger} \\
{[23,25]} \\
\text { Eq }(\text { G. } 1)^{\dagger} \\
{[50]} \\
{[51]}\end{array}$ \\
\hline $\begin{array}{l}\text { Measured } \\
\text { Param- } \\
\text { eters at } \\
t=0 \\
\text { day }\end{array}$ & $\begin{array}{l}\mathrm{d}_{\mathrm{S}, \mathrm{CLL}} \\
\mathrm{l}_{\mathrm{S}, \mathrm{CLL}} \\
\mathrm{d}_{\mathrm{LN}, \mathrm{CLL}} \\
\% \mathrm{Ki}-67_{i} \\
\% \mathrm{BM}_{\mathrm{lymph}} \\
\mathrm{V}_{\mathrm{CLL}, \mathrm{LN}} \\
\mathrm{Nu}_{\mathrm{LN}, d_{\mathrm{LN}, \mathrm{CLL}}} \\
\mathrm{V}_{\mathrm{CLL}, \mathrm{S}}\end{array}$ & $\begin{array}{l}{[5,10]} \\
{[11,28]} \\
{[\geq 1,6]}\end{array}$ & $\begin{array}{l}\mathrm{cm} \\
\mathrm{cm} \\
\mathrm{cm} \\
\% \\
\% \\
\mathrm{~cm}^{3}\end{array}$ & $\begin{array}{l}\text { Enlarged spleen diameter } \\
\text { Enlarged spleen length } \\
\text { Enlarged lymph node diameter } \\
\text { Percentage of Ki-67 in compartments } \forall i \in\{\mathrm{NC}, \mathrm{BM}, \mathrm{PB}, \mathrm{LN}\} \\
\text { Percentage of lymphocytes in bone marrow } \\
\text { Volume of an enlarged lymph node } \\
\text { Number of enlarged lymph nodes of diameter } \mathrm{d}_{\mathrm{LN}, \mathrm{CLL}} \\
\text { Volume of CLL cells in spleen }\end{array}$ & $\begin{array}{l}\text { Table G. } 1^{\dagger} \\
\text { Table G. } 1^{\dagger} \\
\text { [7] } \\
\text { Eq (4) } \\
\text { Eq (5) } \\
\text { Eq }(\text { G. } 2)^{\dagger} \\
\text { Eq }(\text { G.5 })^{\dagger} \\
\text { Eq }(\text { G. } 7)^{\dagger}\end{array}$ \\
\hline $\begin{array}{l}\text { Initial } \\
\text { Conditions }\end{array}$ & $\begin{array}{l}\mathrm{N}_{\mathrm{BM}}, \mathrm{P}_{\mathrm{BM}} \\
\mathrm{N}_{\mathrm{PB}}, \mathrm{P}_{\mathrm{PB}} \\
\mathrm{N}_{\mathrm{LN}}, \mathrm{P}_{\mathrm{LN}}\end{array}$ & & $\begin{array}{l}\text { cells } \\
\text { cells } \\
\text { cells }\end{array}$ & $\begin{array}{l}\% \mathrm{Ki}-67_{\mathrm{BM}} \text { and } \% \mathrm{BM} \text { in } \mathrm{Eq} 5 \\
\% \mathrm{Ki}-67_{\mathrm{PB}} \text { and blood tests } \\
\% \mathrm{Ki}-67_{\mathrm{LN}} \text { and CT scans }\end{array}$ & \\
\hline & $\delta_{i, z}$ & & 1/day & $\begin{array}{l}\text { Cell death rate in quiescent phase } \forall i \in\{\mathrm{NC}, \mathrm{BM}, \mathrm{PB}, \mathrm{LN}\} \\
\delta_{\mathrm{BM}} \in[0.001,0.080] ; \delta_{\mathrm{PB}} \in[0.001,0.020] ; \delta_{\mathrm{LN}} \in[0.001,0.020]\end{array}$ & $\begin{array}{l}{[23,25]} \\
{[30,32]}\end{array}$ \\
\hline $\begin{array}{l}\text { Calculated } \\
\text { Parameters }\end{array}$ & $\gamma_{i, z}$ & & $1 /$ day & $\begin{array}{l}\text { Rate of cell loss from proliferating phase } \forall i \in\{\mathrm{NC}, \mathrm{BM}, \mathrm{PB}, \mathrm{LN}\} \\
\gamma_{\mathrm{BM}} \in[0.001,1.000] ; \gamma_{\mathrm{PB}} \in[0.001,1.000] ; \gamma_{\mathrm{LN}} \in[0.001,1.000]\end{array}$ & $\begin{array}{l}{[23,25]} \\
{[30,32]}\end{array}$ \\
\hline & $\tau_{i, z}$ & {$[0.625,0.792]$} & day & Time spent in proliferative phase in compartments $i \in\{\mathrm{NC}, \mathrm{BM}, \mathrm{PB}, \mathrm{LN}\}$ & [29] \\
\hline & $\begin{array}{l}k_{\mathrm{N}, \mathrm{h}, z} ; k_{\mathrm{P}, \mathrm{h}, z} \\
\theta_{i, 1, z} ; \theta_{i, 2, z}\end{array}$ & & $\begin{array}{l}1 / \text { day } \\
\text { cells }\end{array}$ & $\begin{array}{l}\text { Migration rate of (non-)proliferative (N/P) cells for net flows } h \\
\text { Parameters of } \theta_{i} \text { function }\end{array}$ & $\begin{array}{l}\text { Appendix } \mathrm{D}^{\dagger} \\
\text { Appendix } \mathrm{D}^{\dagger}\end{array}$ \\
\hline Variables & $\begin{array}{l}\theta_{i} \\
\beta_{i} \\
\mathrm{~V}_{\mathrm{CLL}, \mathrm{LN}}^{*} \\
(\mathrm{~N}+\mathrm{P})_{\mathrm{CLL}, \mathrm{LN}} \\
\mathrm{Nu}_{\mathrm{LN}, d_{\mathrm{LN}, \mathrm{CLL}}} \\
\mathrm{V}_{\mathrm{CLL}, \mathrm{S}}^{*} \\
(N+P)_{\mathrm{CLL}, \mathrm{S}} \\
\mathrm{cc} \\
\mathrm{d}_{\mathrm{S}, \mathrm{CLL}} \\
\mathrm{l}_{\mathrm{S}, \mathrm{CLL}} \\
\mathrm{d}_{\mathrm{LN}, \mathrm{CLL}} \\
\% \mathrm{Ki}-67_{i} \\
\% \mathrm{BM} \\
\mathrm{V}_{\mathrm{CLL}, \mathrm{LN}} \\
\mathrm{V}_{\mathrm{CLL}, \mathrm{S}} \\
\mathrm{N}_{i, \tau_{i}, z} \\
\mathrm{~N}_{i}\left(t-\tau_{i, z}\right)\end{array}$ & $\begin{array}{l}{[5,10]} \\
{[11,28]} \\
{[\geq 1,6]}\end{array}$ & $\begin{array}{l}\mathrm{cm} \\
\mathrm{cm} \\
\mathrm{cm} \\
\% \\
\% \\
\mathrm{~cm}^{3} \\
\mathrm{~cm}^{3} \\
\text { cells } \\
\text { cells }\end{array}$ & $\begin{array}{l}\text { Control shape of the feedback function } \forall i \in\{\mathrm{NC}, \mathrm{BM}, \mathrm{PB}, \mathrm{LN}\} \\
\text { Hill feedback function } \\
\text { Volume of an enlarged lymph node based on lymphocytes } \\
\text { Number of CLL cells per lymph node } \\
\text { Number of enlarged lymph nodes of diameter } \mathrm{d}_{\mathrm{LN}}, \mathrm{CLL} \\
\text { Volume of CLL cells in spleen } \\
\text { Total number of CLL cells in spleen } \\
\text { Bone marrow carrying capacity } \\
\text { Enlarged spleen diameter } \\
\text { Enlarged spleen length } \\
\text { Enlarged lymph node diameter } \\
\text { Percentage of Ki-67 in compartments } \forall i \in\{\mathrm{NC}, \mathrm{BM}, \mathrm{PB}, \mathrm{LN}\} \\
\text { Percentage of lymphocytes in bone marrow } \\
\text { Volume of an enlarged lymph node } \\
\text { Volume of CLL cells in spleen } \\
\text { Number of CLL cells in tissues at time } t-\tau_{i} \text { at stage } \mathrm{z} \\
\text { Number of CLL cells in tissues at time } t-\tau_{i} \text { at stage } \mathrm{z}\end{array}$ & $\begin{array}{l}\text { Eq (3) } \\
\text { Eq (D.7) } \\
\text { Eq (G.3) } \\
\text { Eq (G.4) } \\
\text { Eq (G.5) } \\
\text { Eq (G.7) } \\
\text { Eq (G.8) } \\
\text { Eq (6) } \\
\text { Table G. } 1^{\dagger} \\
\text { Table G. } 1^{\dagger} \\
\text { [7] } \\
\text { Eq (4) } \\
\text { Eq (5) } \\
\text { Eq (G.2) } \\
\text { Eq (G.7) } \\
\text { Eq (1) } \\
\text { Eq (1) }\end{array}$ \\
\hline
\end{tabular}

\footnotetext{
$\dagger$ Material in the Online Supplementary Material
} 


\section{Supplementary Material}

A Personalized Framework for Dynamic Modeling of Disease Trajectories in Chronic Lymphocytic Leukemia

Savvopoulos • Misener • Panoskaltsis • Pistikopoulos

- Mantalaris

APPENDIX A

BASIC G0 Cell CyCle Model

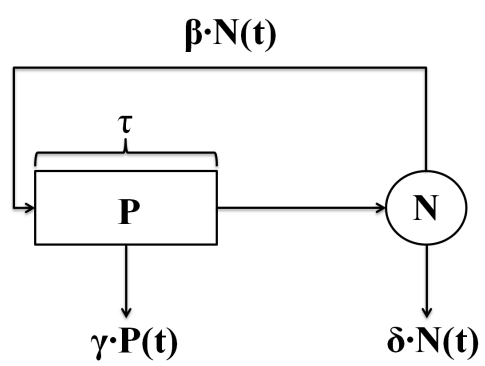

Fig. A.1: The G0 cell cycle model [23, 25]

We represent lymphocyte proliferation using the 2compartment delay differential equation (DDE) model illustrated in Fig. A.1 [23, 25]. The non-proliferative compartment $N$ [cells] represents the resting (G0) phase and the proliferative compartment $P$ [cells] aggregates the remaining cell cycle phases $(\mathrm{G} 1, \mathrm{~S}, \mathrm{G} 2, \mathrm{M})$. Nonproliferative cells migrate to the proliferative compartment where they divide in fixed time $\tau$ (day); the time delay is represented $N_{\tau}=N(t-\tau)$. In the case of normal lymphocytes (NC):

$$
\begin{aligned}
\frac{d N_{\mathrm{NC}}}{d t}= & -\delta_{\mathrm{NC}} N_{\mathrm{NC}}-\beta_{\mathrm{NC}}\left(N_{\mathrm{NC}}\right) N_{\mathrm{NC}} \\
& +2 \beta_{\mathrm{NC}}\left(N_{\tau_{\mathrm{NC}}, \mathrm{NC}}\right) N_{\tau_{\mathrm{NC}}, \mathrm{NC}} e^{-\gamma_{\mathrm{NC}} \tau_{\mathrm{NC}}} \\
\frac{d P_{\mathrm{NC}}}{d t}= & -\gamma_{\mathrm{NC}} P_{\mathrm{NC}}+\beta_{\mathrm{NC}}\left(N_{\mathrm{NC}}\right) N_{\mathrm{NC}} \\
& -\beta_{\mathrm{NC}}\left(N_{\tau_{\mathrm{NC}}, \mathrm{NC}}\right) N_{\tau_{\mathrm{NC}}, \mathrm{NC}} e^{-\gamma_{\mathrm{NC}} \tau_{\mathrm{NC}}}
\end{aligned}
$$

The feedback from non-proliferative to proliferative compartment is given by $\beta$ (1/day) with maximum entry rate $\beta_{N, 0}$ (1/day) and control shape $n, \theta$ (cells) of Eq (D.7). The apoptotic rate in the non-proliferative and proliferative compartments is $\delta$ (1/day) and $\gamma(1 /$ day $)$, respectively $[23,25]$.

\section{APPENDIX B}

\section{PERCENTAGE OF LYMPHOCYTES IN BONE MARROW} AND BONE MARROW CARRYING CAPACITY

The mean lymphocyte percentage in healthy human bone marrow biopsies is $a_{\mathrm{BM}}=25 \%$ (Range: $9-37 \%$ ) [38]. From Table 2, the total number of lymphocytes in bone marrow is $C_{\mathrm{NC}, \mathrm{BM}}=50 \times 10^{9}$. If healthy bone marrow could be evacuated, the total number of analysed cells would be roughly $C_{\mathrm{NC}}$, BM $/ a_{\mathrm{BM}}$ and we can use

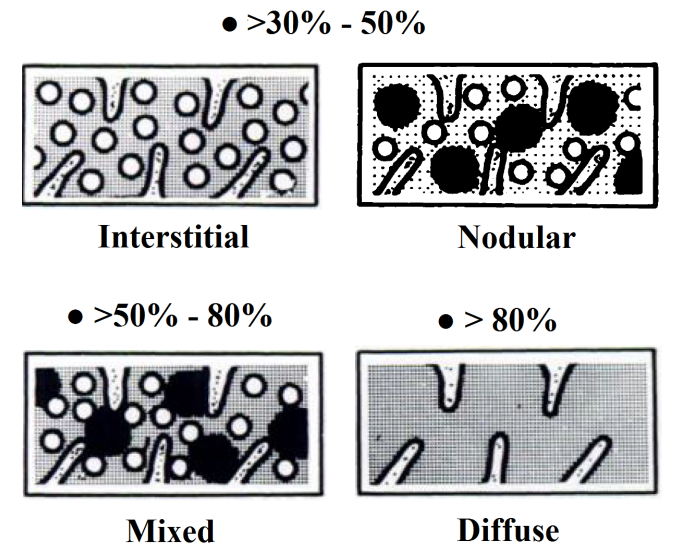

Fig. C.1: CLL BM infiltration patterns [6, 28]; BM infiltration pattern, $\% \mathrm{BM}_{\mathrm{CLL}}$, is typically nodular or interstitial in Naïve stage or Binet Stage A \& B, mixed in Binet Stage B \& C and diffuse in Binet Stage C

Eq 5 to calculate $\% \mathrm{BM}_{\mathrm{lymph}}$, the increased bone marrow lymphocyte percentage due to CLL. Observe in Figure F.2 that $a_{\mathrm{BM}}$ is relatively unimportant in the model

The maximum fraction of CLL cells in BM is $90 \%$. Assuming a constant number $\left(50 \times 10^{9}\right)$ of normal BM lymphocytes [21, 22], we estimate a maximum of $13.5 \times$ $10^{11}$ lymphocytes in heavily-infiltrated BM:

$$
\begin{array}{r}
\% \mathrm{BM}_{\text {lymph }}=\frac{C_{\mathrm{NC}, \mathrm{BM}}+N_{\mathrm{BM}}+P_{\mathrm{BM}}}{\frac{1}{a_{\mathrm{BM}}} C_{\mathrm{NC}, \mathrm{BM}}+P_{\mathrm{BM}}+N_{\mathrm{BM}}} \Leftrightarrow \\
90 \%=\frac{50 \times 10^{9}+N_{\mathrm{BM}}+P_{\mathrm{BM}}}{\frac{1}{25 \%} 50 \times 10^{9}+N_{\mathrm{BM}}+P_{\mathrm{BM}}} \Leftrightarrow \\
N_{\mathrm{BM}}+P_{\mathrm{BM}}=13.0 \times 10^{11}
\end{array}
$$

\section{APPENDIX C \\ CALCULATING THE BONE MARROW INFILTRATION PATTERN}

Accumulating CLL cells may increase the proportion and change the infiltration pattern of BM lymphocytes; lymphocytes typically represent $24.7 \pm 9.6 \%$ of white blood cells (WBCs) on healthy human BM aspirates but may be $>80 \%$ in later CLL stages [38]. Fig. C.1 diagrams the four CLL BM infiltration patterns: interstitial; nodular; mixed; diffuse [28]. In the interstitial pattern, the lymphocyte percentage ranges $30-$ $50 \%$ (light BM infiltration) [6, 28]; mature lymphocytes replace hematopoietic tissue to some degree but BM structure and fat cells are preserved. In the nodular pattern, the lymphocyte percentage also ranges $30-$ $50 \%$, fat cells are preserved and there is no interstitial infiltration $[6,28]$, but nodules of mature lymphocytes 
appear with diameter longer than the lymphoid follicles. In mixed pattern, the percentage of lymphocytes ranges $50-80 \%$ (moderate BM infiltration) $[6,28]$ and there is both interstitial and nodular infiltration. In diffuse pattern, the percentage of lymphocytes is $>80 \%$ (heavy BM infiltration) $[6,28]$ and there is massive replacement of hematopoietic tissue by mature lymphocytes.

\section{APPENDIX D}

\section{PARAMETER ESTIMATION}

In a CLL disease stage $z \in\{\mathrm{SN}, \mathrm{SA}, \mathrm{SB}, \mathrm{SC}\}$, both $t=t_{\text {in }}$ and $t=t_{\text {fin }}$ should require:

$$
\begin{aligned}
& -\delta_{\mathrm{BM}, z} N_{\mathrm{BM}, t, z}-\beta_{\mathrm{BM}}\left(N_{\mathrm{BM}, t, z}\right) N_{\mathrm{BM}, t, z} c c_{t, z} \\
& +2 \beta_{\mathrm{BM}}\left(N_{\mathrm{BM}, t, z}\right) N_{\mathrm{BM}, t, z} e^{-\gamma_{\mathrm{BM}, z} \tau_{\mathrm{BM}, z}} c c_{t, z} \\
& -k_{\mathrm{N}, \mathrm{BM} 2 \mathrm{~PB}, z} N_{\mathrm{BM}, t, z}=\frac{N_{\mathrm{BM}, \text { fin }, z}-N_{\mathrm{BM}, \mathrm{in}, z}}{t_{\mathrm{fin}, z}-t_{\mathrm{in}, z}} \\
& -\delta_{\mathrm{PB}, z} N_{\mathrm{PB}, t, z}-\beta_{\mathrm{PB}}\left(N_{\mathrm{PB}, t, z}\right) N_{\mathrm{PB}, t, z} \\
& +2 \beta_{\mathrm{PB}}\left(N_{\mathrm{PB}, t, z}\right) N_{\mathrm{PB}, t, z} e^{-\gamma_{\mathrm{PB}, z} \tau_{\mathrm{PB}, z}} \\
& +k_{\mathrm{N}, \mathrm{BM} 2 \mathrm{~PB}, z} N_{\mathrm{BM}, t, z}-k_{\mathrm{N}, \mathrm{PB} 2 \mathrm{LN}, z} N_{\mathrm{PB}, t, z} \\
& =\frac{N_{\mathrm{PB}, \text { fin }, z}-N_{\mathrm{PB}, \text { in }, z}}{t_{\text {fin }, z}-t_{\text {in }, z}} \\
& -\delta_{\mathrm{LN}, z} N_{\mathrm{LN}, t, z}-\beta_{\mathrm{LN}}\left(N_{\mathrm{LN}, t, z}\right) N_{\mathrm{LN}, t, z} \\
& +2 \beta_{\mathrm{LN}}\left(N_{\mathrm{LN}, t, z}\right) N_{\mathrm{LN}, t, z} e^{-\gamma_{\mathrm{LN},} z \tau_{\mathrm{LN},} z} \\
& +k_{\mathrm{N}, \text { PB2LN, } z} N_{\mathrm{PB}, t, z}=\frac{N_{\mathrm{LN}, \text { fin }, z}-N_{\mathrm{LN}, \text { in }, z}}{t_{\mathrm{fin}, z}-t_{\mathrm{in}, z}} \\
& -\gamma_{\mathrm{BM}, z} P_{\mathrm{BM}, t, z}+\beta_{\mathrm{BM}}\left(N_{\mathrm{BM}, t, z}\right) N_{\mathrm{BM}, t, z} c c_{t, z} \\
& -\beta_{\mathrm{BM}}\left(N_{\mathrm{BM}, t, z}\right) N_{\mathrm{BM}, t, z} e^{-\gamma_{\mathrm{BM}, z} \tau_{\mathrm{BM}, z}} c c_{t, z} \\
& -k_{\mathrm{P}, \mathrm{BM} 2 \mathrm{~PB}, z} P_{\mathrm{BM}, t, z}=\frac{P_{\mathrm{BM}, \mathrm{fin}, z}-P_{\mathrm{BM}, \mathrm{in}, z}}{t_{\mathrm{fin}, z}-t_{\mathrm{in}, z}} \\
& -\gamma_{\mathrm{PB}, z} P_{\mathrm{PB}, t, z}+\beta_{\mathrm{PB}}\left(N_{\mathrm{PB}, t, z}\right) N_{\mathrm{PB}, t, z} \\
& -\beta_{\mathrm{PB}}\left(N_{\mathrm{PB}, t, z}\right) N_{\mathrm{PB}, t, z} e^{-\gamma_{\mathrm{PB}, z} \tau_{\mathrm{PB}, z}} \\
& +k_{\mathrm{P}, \mathrm{BM} 2 \mathrm{~PB}, z} P_{\mathrm{BM}, t, z}-k_{\mathrm{P}, \mathrm{PB} 2 \mathrm{LN}, z} P_{\mathrm{PB}, t} \\
& =\frac{P_{\mathrm{PB}, \mathrm{fin}, z}-P_{\mathrm{PB}, \mathrm{in}, z}}{t_{\mathrm{fin}, z}-t_{\mathrm{in}, z}} \\
& -\gamma_{\mathrm{LN}, z} P_{\mathrm{LN}, t, z}+\beta_{\mathrm{LN}}\left(N_{\mathrm{LN}, t, z}\right) N_{\mathrm{LN}, t, z} \\
& -\beta_{\mathrm{LN}}\left(N_{\mathrm{LN}, t, z}\right) N_{\mathrm{LN}, t, z} e^{-\gamma_{\mathrm{LN}, z} \tau_{\mathrm{LN}, z}} \\
& +k_{\mathrm{P}, \mathrm{PB} 2 \mathrm{LN}, z} P_{\mathrm{PB}, t, z}=\frac{P_{\mathrm{LN}, \text { fin }, z}-P_{\mathrm{LN}, \text { in }, z}}{t_{\mathrm{fin}, z}-t_{\mathrm{in}, z}}
\end{aligned}
$$

where $i \in\{\mathrm{BM}, \mathrm{PB}, \mathrm{LN}\}$ and $z \in\{\mathrm{SN}, \mathrm{SA}, \mathrm{SB}, \mathrm{SC}\}$

$$
\begin{aligned}
\beta_{i}\left(N_{i, t, z}\right) & =\beta_{N_{i}, 0} /\left(1+\left(u_{i, t, z}\right)^{n_{i}}\right) \\
u_{i, t, z} & =N_{i, t, z} / \theta_{i, t, z} \\
\theta_{i, 2, z} & =\theta_{i, t_{\text {in }}, z} \\
\theta_{i, 1, z} & =\frac{\theta_{i, t_{\text {fin }}, z}-\theta_{i, t_{\text {in }}, z}}{t_{\text {fin }, z}-t_{\text {in }, z}} \\
\theta_{i} & =\theta_{i, 1, z}\left(t-t_{\mathrm{in}, z}\right)+\theta_{i, 2, z} .
\end{aligned}
$$

Furthermore, we assume:

(a) The constraints of $u_{i, t, z}$ are:

$$
\begin{array}{ll}
u_{\mathrm{BM}}^{\mathrm{LB}}=2 \leq u_{\mathrm{BM}, t, z} \leq u_{\mathrm{BM}}^{\mathrm{UB}} & =20 \\
u_{\mathrm{PB}}^{\mathrm{LB}} & =u_{\mathrm{PB}}^{\mathrm{UB}} \\
u_{\mathrm{LN}}^{\mathrm{LB}} & =2 \leq u_{\mathrm{LN}, t, z} \leq u_{\mathrm{PB}, t, z}
\end{array}
$$

If $N_{\mathrm{LN}, t_{\text {in }}, z}+P_{\mathrm{LN}, t_{\text {in }}, z} \simeq 0$ then $u_{\mathrm{LN}, t_{\text {in }}, z}=u_{\mathrm{PB}, t_{\text {in }}, z}$

(b) Apoptotic rates bounds from Table 7 [1/day]:

$$
\begin{gathered}
\delta_{\mathrm{BM}}^{\mathrm{LB}}=0.001 \leq \delta_{\mathrm{BM}, z} \leq \delta_{\mathrm{BM}}^{\mathrm{UB}}=0.080 \\
\delta_{\mathrm{PB}}^{\mathrm{LB}}=0.001 \leq \delta_{\mathrm{PB}, z} \leq \delta_{\mathrm{PB}}^{\mathrm{LB}}=0.020 \\
\delta_{\mathrm{LN}}^{\mathrm{LB}}=0.001 \leq \delta_{\mathrm{LN}, z} \leq \delta_{\mathrm{LN}}^{\mathrm{UB}}=0.020 \\
\gamma_{i}^{\mathrm{LB}}=0.001 \leq \gamma_{i, z} \leq \gamma_{i}^{\mathrm{UB}}=1.000
\end{gathered}
$$

(c) Apoptotic rates for proliferating cells may be high when they lose contact with $\mathrm{T}$ cells [52].

$$
\gamma_{i, z} \geq \delta_{i, z}
$$

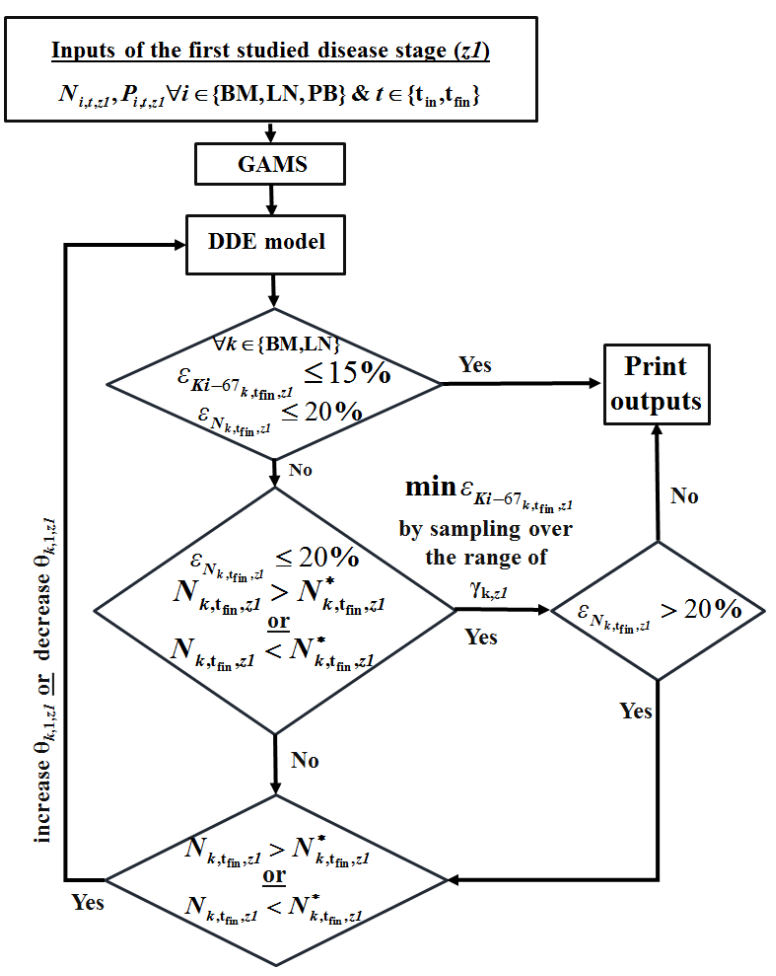

Fig. D.1: Iterative procedure for disease stage $z 1$; subsequent stages are equivalent. Intermediate MATLAB outputs (marked *) should match Table E.1 (no*)

(d) Migration rate lower and upper bounds are 0.001 and 1.000 , respectively. We assume lower migration rates for proliferating cells than non-proliferating cells in bone marrow because of the niche:

$$
k_{\mathrm{P}, \mathrm{BM} 2 \mathrm{~PB}, z} \leq k_{\mathrm{N}, \mathrm{BM} 2 \mathrm{~PB}, z}
$$

(e) If CLL cells are accumulating in PB, use Eq (D.21), otherwise use Eq (D.22):

$$
\begin{aligned}
& N_{\mathrm{BM}, \text { fin }, z} \geq \frac{k_{\mathrm{N}, \mathrm{PB} 2 \mathrm{LN}, z}}{k_{\mathrm{N}, \mathrm{BM} 2 \mathrm{~PB}, z}} N_{\mathrm{PB}, \text { fin }, z} \\
& N_{\mathrm{BM}, \text { fin, }, z} \leq \frac{k_{\mathrm{N}, \mathrm{PB} 2 \mathrm{LN}, z}}{k_{\mathrm{N}, \mathrm{BM} 2 \mathrm{~PB}, z}} N_{\mathrm{PB}, \text { fin }, z}
\end{aligned}
$$


(f) Migration rates from $\mathrm{PB}$ to $\mathrm{LN}$ are related to the $\mathrm{Ki}-67$ fraction listed in Table 5 for each tissue:

$$
\begin{aligned}
& \frac{k_{\mathrm{P}, \mathrm{PB} 2 \mathrm{LN}, z}}{k_{\mathrm{N}, \mathrm{PB} 2 \mathrm{LN}, z}} \cdot \frac{P_{\mathrm{PB}}}{N_{\mathrm{PB}}} \leq \mathrm{Ki}-67_{\mathrm{LN}, \mathrm{AV}} \Rightarrow \\
& k_{\mathrm{P}, \mathrm{PB} 2 \mathrm{LN}, z} \leq k_{\mathrm{N}, \mathrm{PB} 2 \mathrm{LN}, z} \frac{\mathrm{Ki}-67_{\mathrm{LN}, \mathrm{AV}}}{\mathrm{Ki}-67_{\mathrm{PB}, \mathrm{AV}}} \text {; }
\end{aligned}
$$

(g) Time [day] spent in proliferative phase [29]:

$$
\tau_{i}^{\mathrm{LB}}=0.625 \leq \tau_{i, z} \leq \tau_{i}^{\mathrm{UB}}=0.792
$$

(h) Only in the parameter estimation:

$$
c c_{t, z}=1
$$

Eqs (D.1) - (D.25), seeded with the initial and final number of cells measured at different time points (Tables $5 \&$ E.1), are solved as a feasibility problem in GAMS. Final conditions at $t=t_{\text {fin }}$ are set by expected values depending on the disease stage (see Tables $1 \&$ C.1 and Appendix C). The GAMS output is a set of parameter values $\tau_{i, z 1}$, $\delta_{i, z 1}, \gamma_{i, z 1}, \theta_{i, 1, z 1}, \theta_{i, 2, z 1}, k_{\mathrm{N}, \mathrm{BM} 2 \mathrm{~PB}, z 1}, k_{\mathrm{P}, \mathrm{BM} 2 \mathrm{~PB}, z 1}$, $k_{\mathrm{N}, \mathrm{PB} 2 \mathrm{LN}, z 1}$ and $k_{\mathrm{P}, \mathrm{PB} 2 \mathrm{BM}, z 1} \forall i \in\{\mathrm{BM}, \mathrm{PB}, \mathrm{LN}\}$, $z 1 \in\{\mathrm{SN}, \mathrm{SA}, \mathrm{SB}\}$ satisfying the constraints.

We enter the output parameters from the GAMS feasibility problem into the set of DDEs in MATLAB and check that final conditions agree with expected values. If the MATLAB output is not as expected, we vary the parameters first in $\mathrm{BM}$ and then in $\mathrm{LN}$ :

(a) If the relative error of $\mathrm{Ki}-67, \varepsilon_{\mathrm{Ki}-67_{k, t_{f i}, z 1}}>15 \%$

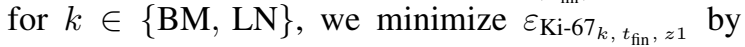
sampling over the lower and upper bound of $\gamma_{k, z 1}$;

$$
\varepsilon_{\mathrm{Ki}-67_{k, t_{\text {fin }}, z 1}}=\frac{\left|\Delta \mathrm{Ki}-67_{k, z 1}\left(t_{\text {fin }}\right)\right|}{\operatorname{Ki}-67_{k, z 1}\left(t_{\text {fin }}\right)}
$$

(b) If the relative error of $N_{k}, \varepsilon_{N_{k}, t_{\text {fin }}, z 1}>20 \%$, we increase or decrease control parameter $\theta_{k, 1, z 1}$ for insufficiency or hypersufficiency, respectively. We increment $\theta_{k, 1, z 1}$ by increasing the highest non-zero digit of the initial $\theta_{k, 1, z 1}$ by 1 until the flowsheet in Fig. D.1 is satisfied:

$$
\varepsilon_{N_{k, t_{\text {fin }}, z 1}}=\frac{\left|\Delta N_{k, z 1}\left(t_{\text {fin }}\right)\right|}{N_{k, z 1}\left(t_{\text {fin }}\right)}
$$

For trajectories spanning two Binet stages, the final values of the first stage are initial conditions for the second disease stage (Table E.1) and, for the second disease stage, only parameters varying within a disease stage, e.g., the control function and migration rates) are calculated by GAMS. Solving for the second disease stage is similar except that we tighten the tolerance in step (a) above to $10 \%$. Recall here that our goal is finding reasonable rather than optimal parameters; Appendix $\mathrm{H}$ demonstrates the results using a multistart strategy since there are multiple possible outputs of the GAMS feasibility problem.

\section{APPENDIX E \\ INITIAL AND FINAL EXPECTED CONDITIONS}

Representing patient heterogeneity, Table 5 posits symptoms of 5 hypothetical patients. For each tissue in each disease stage, we estimate the fraction of proliferative cells using expected Ki-67 expression (Table 5). PB lymphocyte counts are based on expected LDT values (Table 1) and BM infiltration patterns are chosen with respect to CLL disease progression (Table C.1).

This study focusses on cells migrating from BM to $\mathrm{PB}$ and then from $\mathrm{PB}$ to $\mathrm{LN}$ and $\mathrm{S}$; initial numbers of enlarged $\mathrm{LN}$ in the 5 patients correspond to expected disease stage. Final CLL cell count is based on expected lymphadenopathy and splenomegaly in CLL. As in PB and $\mathrm{BM}$, the expected proliferative cell fraction in $\mathrm{LN}$ and $\mathrm{S}$ is based on expected values of Ki-67 (Table 5).

\section{APPENDIX F \\ Global Sensitivity Analysis}

RS-HDMR, like the Sobol global sensitivity analysis method, decomposes model output into summands of increasing dimensionality [36].

$$
\begin{aligned}
f(\mathbf{x})=f_{0} & +\sum_{i=1}^{n} f_{i}\left(x_{i}\right) \\
& +\sum_{i, j}^{n} f_{i, j}\left(x_{i}, x_{j}\right)+\ldots+f_{1,2, \ldots, n}(\mathbf{x})
\end{aligned}
$$

where:

$$
\begin{aligned}
& f_{0}=\int_{K^{n}} f(\mathbf{x}) \mathrm{d} \mathbf{x} \\
& f_{i}\left(x_{i}\right)=\int_{K^{n-1}} f(\mathbf{x}) \mathrm{d} \mathbf{x}^{i}-f_{0} \\
& f_{i j}\left(x_{i}, x_{j}\right)=\int_{K^{n-2}} f(\mathbf{x}) \mathrm{d} \mathbf{x}^{i j}-f_{i}\left(x_{i}\right)-f_{j}\left(x_{j}\right)-f_{0} \\
& \ldots
\end{aligned}
$$

and $\mathbf{x}=\left[x_{1}, x_{2}, \ldots, x_{n}\right]$ is the input of parameters whose values change; $\mathrm{d} \mathbf{x}^{i}$ is the product $\mathrm{d} x_{1} \mathrm{~d} x_{2} \ldots \mathrm{d} x_{n}$; $\mathrm{d} \mathbf{x}^{i j}$ is the same product without $\mathrm{d} x_{i}$ and $\mathrm{d} x_{j}$. This decomposition, also called analysis of variance (ANOVA), creates unique, orthogonal terms and reveals both firstand higher-order effects to model output via variancebased methods. The total variance $D$ is [53]:

$$
D=\int_{K^{n}} f^{2}(\mathbf{x}) \mathrm{d} \mathbf{x}-f_{0}^{2}
$$

and the partial variances $D_{i_{1}}, \ldots, i_{s}$ are calculated by:

$$
\begin{aligned}
D_{i} & =\int_{0}^{1} f_{i}^{2}\left(x_{i}\right) \mathrm{d} x_{i} \\
D_{i j} & =\int_{0}^{1} \int_{0}^{1} f_{i, j}^{2}\left(x_{i}, x_{j}\right) \mathrm{d} x_{i} \mathrm{~d} x_{j} \quad \ldots
\end{aligned}
$$


TABLE E.1: Initial and final conditions in hypothetical patients P1 - P5 and initial steps in GAMS

\begin{tabular}{|c|c|c|c|c|}
\hline \multicolumn{5}{|c|}{ Patient 1 (P1) } \\
\hline & Naïve initial ( 0 day) & Naïve final (1000 day) & Binet A initial (1000 day) & Binet A final (3190 day) \\
\hline $\mathrm{N}_{\mathrm{BM}}\left(\cdot 10^{8}\right.$ cells $)$ & 380.000 & 380.010 & 380.010 & 667.000 \\
\hline $\mathrm{N}_{\mathrm{LN}}\left(\cdot 10^{8}\right.$ cells $)$ & 0.010 & 912.000 & 912.000 & 3662.000 \\
\hline $\mathrm{N}_{\mathrm{PB}}\left(\cdot 10^{8}\right.$ cells $)$ & 300.000 & 329.000 & 329.000 & 660.000 \\
\hline $\mathrm{P}_{\mathrm{BM}}\left(\cdot 10^{8}\right.$ cells $)$ & 10.500 & 13.500 & 13.500 & 19.000 \\
\hline $\mathrm{P}_{\mathrm{LN}}\left(\cdot 10^{8}\right.$ cells $)$ & 0.000 & 42.000 & 42.000 & 172.500 \\
\hline $\mathrm{P}_{\mathrm{PB}}\left(\cdot 10^{8}\right.$ cells $)$ & 0.900 & 1.500 & 1.500 & 2.380 \\
\hline What changed to $2^{\text {nd }}$ stage & & & \multicolumn{2}{|c|}{ only $\theta \mathrm{s}$ and migration rates change in GAMS } \\
\hline \multicolumn{5}{|c|}{ Patient 2 (P2) } \\
\hline & Binet $\mathrm{A}$ initial (0 day) & Binet A final (1800 day) & Binet $B$ initial (1800 day) & Binet $B$ final (2165 day) \\
\hline $\mathrm{N}_{\mathrm{BM}}\left(\cdot 10^{8}\right.$ cells $)$ & 800.000 & 1108.000 & 1108.000 & 1815.000 \\
\hline $\mathrm{N}_{\mathrm{LN}}\left(\cdot 10^{8}\right.$ cells $)$ & 1300.000 & 2075.000 & 2075.000 & 2556.000 \\
\hline $\mathrm{N}_{\mathrm{PB}}\left(\cdot 10^{8}\right.$ cells $)$ & 400.000 & 661.000 & 661.000 & 1423.000 \\
\hline $\mathrm{P}_{\mathrm{BM}}\left(\cdot 10^{8}\right.$ cells $)$ & 15.900 & 33.110 & 33.110 & 60.000 \\
\hline $\mathrm{P}_{\mathrm{LN}}\left(\cdot 10^{8}\right.$ cells $)$ & 40.000 & 97.800 & 97.800 & 132.000 \\
\hline $\mathrm{P}_{\mathrm{PB}}\left(\cdot 10^{8}\right.$ cells $)$ & 0.810 & 2.380 & 2.380 & 5.140 \\
\hline What changed to $2^{\text {nd }}$ stage & & & all parameters change & in GAMS except $\tau \mathrm{s}$ \\
\hline \multicolumn{5}{|c|}{ atie } \\
\hline & Binet $A$ initial (0 day) & Binet A final (365 day) & Binet B initial (365 day) & Binet $B$ final (730 day) \\
\hline $\mathrm{N}_{\mathrm{BM}}\left(\cdot 10^{8}\right.$ cells $)$ & 800.000 & 1108.000 & 1108.000 & 1750.000 \\
\hline $\mathrm{N}_{\mathrm{LN}}\left(\cdot 10^{8}\right.$ cells $)$ & 1300.000 & 2550.000 & 2550.000 & 3877.000 \\
\hline $\mathrm{N}_{\mathrm{PB}}\left(\cdot 10^{8}\right.$ cells $)$ & 400.000 & 862.000 & 862.000 & 1826.000 \\
\hline $\mathrm{P}_{\mathrm{BM}}\left(\cdot 10^{8}\right.$ cells $)$ & 15.900 & 33.110 & 33.110 & 58.000 \\
\hline $\mathrm{P}_{\mathrm{LN}}\left(\cdot 10^{8}\right.$ cells $)$ & 40.000 & 120.158 & 120.158 & 212.000 \\
\hline $\mathrm{P}_{\mathrm{PB}}\left(\cdot 10^{8}\right.$ cells $)$ & 0.810 & 3.113 & 3.113 & 6.591 \\
\hline What changed to $2^{\text {nd }}$ stage & & & only $\theta \mathrm{s}$ and migration & ates change in GAMS \\
\hline \multicolumn{5}{|c|}{ ati } \\
\hline & Binet $B$ initial (0 day) & Binet B final (365 day) & Binet $C$ initial (365 day) & Binet $\mathrm{C}$ final (730 day) \\
\hline $\mathrm{N}_{\mathrm{BM}}\left(\cdot 10^{8}\right.$ cells $)$ & 1100.000 & 1933.000 & 1933.000 & 4934.000 \\
\hline $\mathrm{N}_{\mathrm{LN}}\left(\cdot 10^{8}\right.$ cells $)$ & 1300.000 & 15806.000 & 15806.000 & 38334.000 \\
\hline $\mathrm{N}_{\mathrm{PB}}\left(\cdot 10^{8}\right.$ cells $)$ & 4200.000 & 9140.000 & 9140.000 & 18332.000 \\
\hline $\mathrm{P}_{\mathrm{BM}}\left(\cdot 10^{8}\right.$ cells $)$ & 34.129 & 57.110 & 57.110 & 158.000 \\
\hline $\mathrm{P}_{\mathrm{LN}}\left(\cdot 10^{8}\right.$ cells $)$ & 26.000 & 744.158 & 744.158 & 2317.000 \\
\hline $\mathrm{P}_{\mathrm{PB}}\left(\cdot 10^{8}\right.$ cells $)$ & 8.410 & 33.114 & 33.114 & 59.591 \\
\hline What changed to $2^{\text {nd }}$ stage & & & only $\theta \mathrm{s}$ and migration & ates change in GAMS \\
\hline \multicolumn{5}{|c|}{ atre } \\
\hline & Binet $\mathrm{A}$ initial (0 day) & Binet A final (365 day) & Binet $C$ initial (365 day) & Binet $C$ final (730 day) \\
\hline $\mathrm{N}_{\mathrm{BM}}\left(\cdot 10^{8}\right.$ cells $)$ & 390.000 & 390.410 & 390.410 & 7030.000 \\
\hline $\mathrm{N}_{\mathrm{LN}}\left(\cdot 10^{8}\right.$ cells $)$ & 1000.000 & 2455.150 & 2455.150 & 7832.000 \\
\hline $\mathrm{N}_{\mathrm{PB}}\left(\cdot 10^{8}\right.$ cells $)$ & 900.000 & 1029.000 & 1029.000 & 2666.000 \\
\hline $\mathrm{P}_{\mathrm{BM}}\left(\cdot 10^{8}\right.$ cells $)$ & 7.000 & 7.390 & 7.390 & 210.000 \\
\hline $\mathrm{P}_{\mathrm{LN}}\left(\cdot 10^{8}\right.$ cells $)$ & 47.110 & 115.500 & 115.500 & 545.000 \\
\hline $\mathrm{P}_{\mathrm{PB}}\left(\cdot 10^{8}\right.$ cells $)$ & 2.000 & 3.713 & 3.713 & 10.000 \\
\hline What changed to $2^{\text {nd }}$ stage & & & \multicolumn{2}{|c|}{ all parameters change in GAMS except $\tau$ s } \\
\hline
\end{tabular}

The sensitivity indices are given by:

$$
S_{i_{1}, \ldots, i_{s}}=\frac{D_{i_{1}, \ldots, i_{s}}}{D}, 1 \leq i_{1}<\ldots<i_{s} \leq n
$$

so that all terms add up to 1 :

$$
\sum_{i=1}^{n} S_{i}+\sum_{1 \leq i<j \leq n} S_{i, j}+\ldots+S_{1,2, \ldots, n}=1
$$

The main effect of the input variable $\mathrm{x}_{i}$ on the output is calculated by the first order sensitivity index $\mathrm{S}_{i}$ while the effect of $\mathrm{x}_{i}$ and $\mathrm{x}_{j}$ on the output is given by the second order sensitivity indices and so on. Fig. parameter ranking is done for each of the model outputs.
Global sensitivity analysis of two compartments, like that in Fig. A.1 with initial conditions $N_{0}=1809 \cdot 10^{8}$ cells, $P_{0}=54 \cdot 10^{8}$ cells and $N / \theta<<20$ (proliferation), shows that the most important parameters in the nonproliferative population are $\theta_{1}>\theta_{2}>\gamma>\beta_{0}>\tau>\delta$ (Fig. F.1) and the most important parameters in the proliferative population are $\gamma>\theta_{1}>\tau>\beta_{0}>$ $\theta_{2}>\delta$ (Fig. F.1). $\theta_{1}$ increases both the non-proliferative and proliferative populations but $\gamma$ decreases the nonproliferative population and increases the proliferative population because it decreases the rate of cells which pass through the proliferative phase.

Table F.1 contains parameters and their relevant ranges for sensitivity analysis; we have previously analyzed a 
TABLE F.1: Ranges of parameters used in RS-HDMR analysis of CLL framework from Binet Stages A to C

\begin{tabular}{|c|c|c|c|c|}
\hline Parameter (Units) & Nominal Value & Minimum Value & Maximum Value & Ref. \\
\hline$\gamma_{\mathrm{BM}}(1 /$ day $)$ & 0.565 & 0.091 & 0.823 & Table 4 \\
\hline$\gamma_{\mathrm{LN}}(1 /$ day $)$ & 0.706 & 0.530 & 0.866 & Table 4 \\
\hline$\gamma_{\mathrm{PB}}(1 /$ day $)$ & 0.001 & 0.001 & 0.003 & Table 4 \\
\hline$\delta_{\mathrm{BM}}(1 /$ day $)$ & 0.001 & 0.001 & 0.037 & Table 4 \\
\hline$\delta_{\mathrm{LN}}(1 /$ day $)$ & 0.001 & 0.001 & 0.020 & Table 4 \\
\hline$\delta_{\mathrm{PB}}(1 /$ day $)$ & 0.001 & 0.001 & 0.003 & Table 4 \\
\hline$\tau_{\mathrm{BM}}$ (day) & 0.792 & 0.625 & 0.792 & [29] \\
\hline$\tau_{\mathrm{LN}}$ (day) & 0.792 & 0.625 & 0.792 & [29] \\
\hline$\tau_{\mathrm{PB}}$ (day) & 0.792 & 0.625 & 0.792 & [29] \\
\hline$\theta_{\mathrm{BM}, 1}\left(\cdot 10^{8}\right.$ cells $)$ & 0.010 & 0.004 & 6.209 & Table 4 \\
\hline$\theta_{\mathrm{BM}, 2}\left(\cdot 10^{8}\right.$ cells $)$ & \multicolumn{3}{|c|}{$3 \leq N_{\mathrm{BM}, 0} / \theta_{\mathrm{BM}, 2} \leq 5$} & Table 4 \\
\hline$\theta_{\mathrm{LN}, 1}\left(\cdot 10^{8}\right.$ cells $)$ & 0.279 & & 19.297 & Table 4 \\
\hline$\theta_{\mathrm{LN}, 2}\left(\cdot 10^{8}\right.$ cells $)$ & \multicolumn{3}{|c|}{$3 \leq N_{\mathrm{LN}, 0} / \theta_{\mathrm{LN}, 2} \leq 4.5$} & Table 4 \\
\hline$\theta_{\mathrm{PB}, 1}\left(\cdot 10^{8}\right.$ cells $)$ & 0.001 & 0.001 & 1.259 & Table 4 \\
\hline$\theta_{\mathrm{PB}, 2}\left(\cdot 10^{8}\right.$ cells $)$ & & \multicolumn{2}{|c|}{$N_{\mathrm{PB}, 0} / \theta_{\mathrm{PB}, 2} \geq 20$} & Table 4 \\
\hline$k_{\mathrm{N}, \mathrm{BM} 2 \mathrm{~PB}}(1 /$ day $)$ & 0.003 & 0.001 & 0.035 & Table 4 \\
\hline$k_{\mathrm{P}, \mathrm{BM} 2 \mathrm{~PB}}(1 /$ day $)$ & 0.001 & 0.001 & 0.003 & Table 4 \\
\hline$k_{\mathrm{N}, \text { PB2LN }}(1 /$ day $)$ & 0.003 & 0.001 & 0.005 & Table 4 \\
\hline$k_{\mathrm{P}, \mathrm{PB} 2 \mathrm{LN}}(1 /$ day $)$ & 0.013 & 0.001 & 0.033 & Table 4 \\
\hline $\mathrm{n}_{\mathrm{BM}}$ & 3 & 2 & 4 & {$[23,43]$} \\
\hline $\mathrm{n}_{\mathrm{LN}}$ & 3 & 2 & 4 & {$[23,43]$} \\
\hline $\mathrm{n}_{\mathrm{PB}}$ & 3 & 2 & 4 & {$[23,43]$} \\
\hline$\beta_{\mathrm{N}_{\mathrm{BM}, 0}}(1 /$ day $)$ & 3.350 & $1.690(-50 \%)$ & $5.070(+50 \%)$ & {$[25]$} \\
\hline$\beta_{\mathrm{N}_{\mathrm{LN}}, 0}(1 /$ day $)$ & 3.350 & $1.690(-50 \%)$ & $5.070(+50 \%)$ & [25] \\
\hline$\beta_{\mathrm{NPB}, 0}(1 /$ day $)$ & 3.350 & $1.690(-50 \%)$ & $5.070(+50 \%)$ & [25] \\
\hline$a_{\mathrm{BM}}$ & 0.25 & 0.09 & 0.37 & [38] \\
\hline $\mathrm{BM}_{\max }\left(\cdot 10^{8}\right.$ cells $)$ & 13500 & $6750(-50 \%)$ & $20250(+50 \%)$ & Appendix B \\
\hline $\mathrm{C}_{\mathrm{NC}, \mathrm{BM}}\left(\cdot 10^{8}\right.$ cells $)$ & 500 & $250(-50 \%)$ & $750(+50 \%)$ & Table 2 \\
\hline$N_{\text {BM, } 0}\left(\cdot 10^{8}\right.$ cells $)$ & 380.000 & 380.000 & 2000.000 & Table 4 \\
\hline$N_{\mathrm{LN}, 0}\left(\cdot 10^{8}\right.$ cells $)$ & 1000.000 & 1000.000 & 15000.000 & Table 4 \\
\hline$N_{\mathrm{PB}, 0}\left(\cdot 10^{8}\right.$ cells $)$ & 300.000 & 300.000 & 9000.000 & Table 4 \\
\hline
\end{tabular}

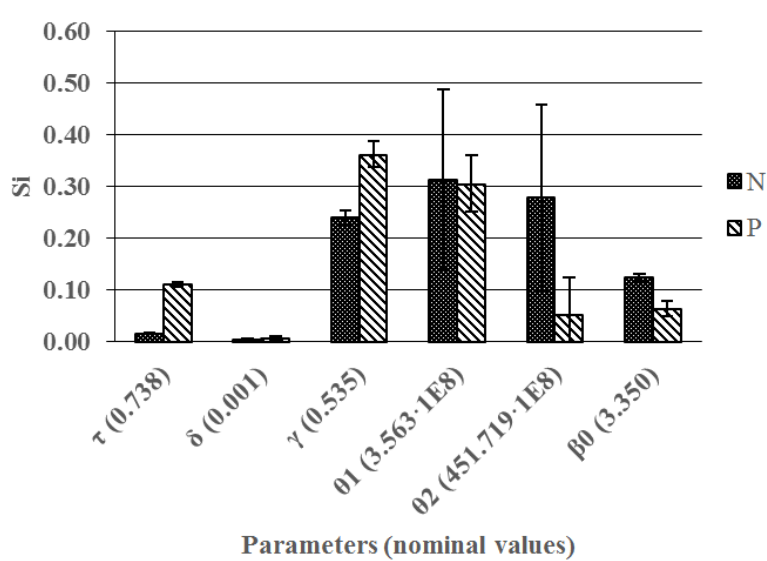

Fig. F.1: Global sensitivity analysis of a two compartmental model in which all the parameters change $\pm 50 \%$ except $\tau \in[0.625,0.792]$ day for 2000 steps

subset of these parameters on a different CLL model [18]. Table F.1 lists ranges for non-proliferative initial conditions but not for proliferative initial conditions because non-proliferative and proliferative tissue are related with respect to $\mathrm{Ki}-67$ measurements (Table 5). In the analysis, the maximum order for approximation of the first and second order component functions is 10 and 5, respectively. Ten iterations are used for both the first and second order component functions.

APPENDIX G

CALCULATING THE NUMBER OF ENLARGED LYMPH
NODES AND PREDICTING THE SPLEEN PATTERN

TABLE G.1: Cases of splenomegaly and spleen size [54]

\begin{tabular}{ll}
\hline Severity & Size (width $\times$ length) \\
\hline Mild to Moderate & $\geq 5 \times 11 \mathrm{~cm}$ \\
Marked & $\geq 6 \times 16 \mathrm{~cm}$ \\
Extreme & $\geq 8 \times 20 \mathrm{~cm}$ \\
\hline
\end{tabular}

The body has $\approx \mathrm{Nu}_{\mathrm{LN}}=800 \mathrm{LN}$ which are the primary defense mechanism against infection [55]; each LN typically has diameter $\mathrm{d}=1-2 \mathrm{~cm}$ and is connected to other LN via lymphatic vessels [49]. We approximate $\mathrm{LN}$ as spheres and $\mathrm{S}$ as a cylinder. What causes the change of the size of $\mathrm{LN}$ and $\mathrm{S}$ is the increased number of migrated CLL cells whose shape can be assumed as spheres with volume $\mathrm{V}_{\mathrm{CLL}}=166 \cdot 10^{-12} \mathrm{~cm}^{3}$ [51]. The sequel explains how we estimate the number of enlarged $\mathrm{LN}$ when either the $\mathrm{S}$ is normal or enlarged.

1) Size \& number of enlarged LN with normal $S$ : 

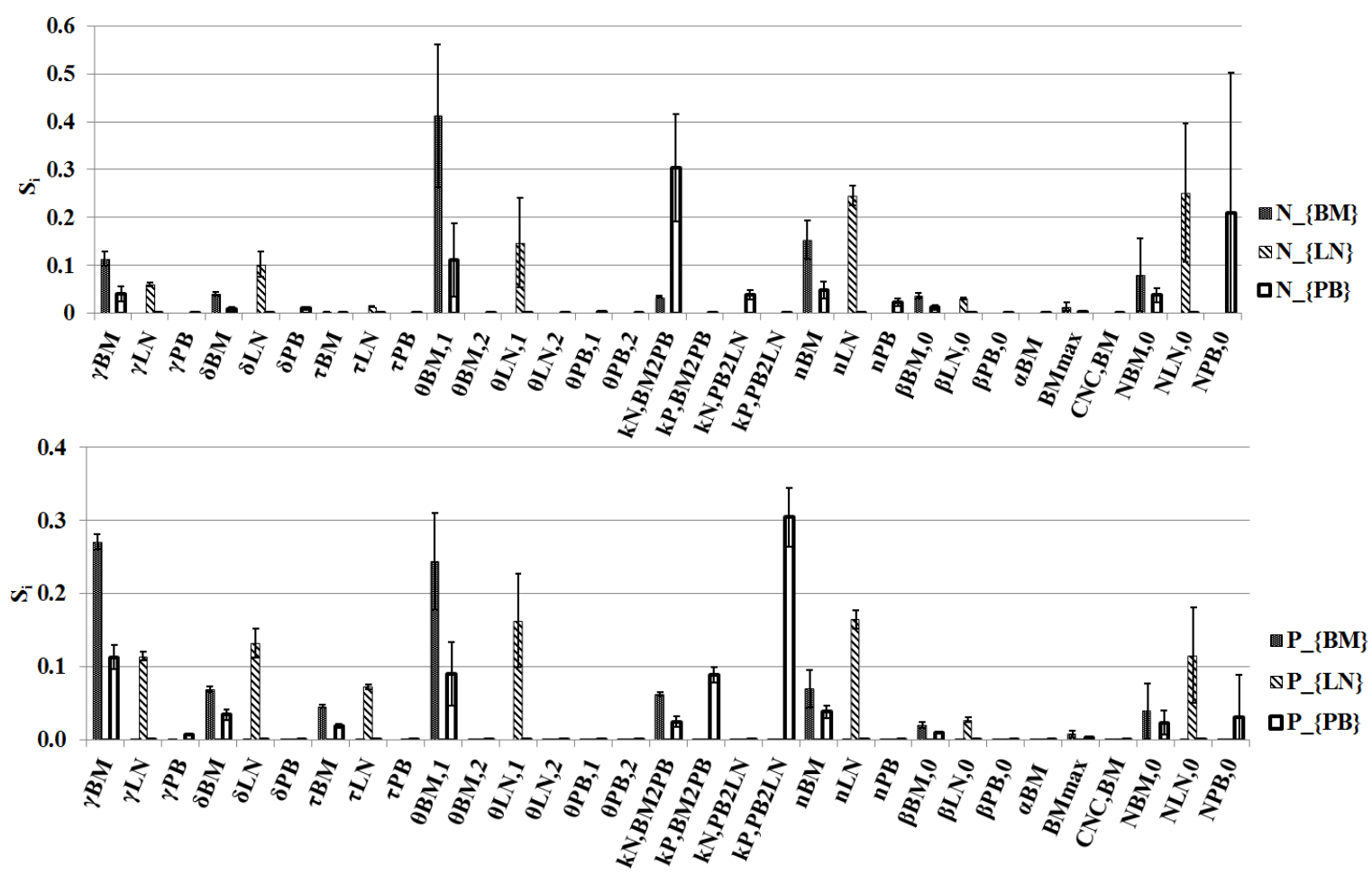

Fig. F.2: Average values of $\mathrm{S}_{i} \pm \mathrm{SD}$ indices in each non-proliferative and proliferative output for hypothetical patients P1 - P5

(a) Calculating LN volume: Each $\mathrm{LN}$ has diameter $\mathrm{d}_{\mathrm{LN}, \mathrm{NC}} \approx 1 \mathrm{~cm}$, so its volume is:

$$
V_{\mathrm{LN}} \approx \frac{4}{3} \pi\left(\frac{1 \mathrm{~cm}}{2}\right)^{3}=0.52 \mathrm{~cm}^{3}
$$

(b) Counting CLL cells in enlarged LN: The volume of $\mathrm{LN}$ with enlarged diameter $\mathrm{d}_{\mathrm{LN}, \mathrm{CLL}}$ is:

$$
V_{\mathrm{CLL}, \mathrm{LN}}=\frac{4}{3} \pi\left(\frac{d_{\mathrm{LN}, \mathrm{CLL}}}{2}\right)^{3}
$$

We assume that normal lymphocyte count is constant, i.e., the tissue is not replaced, so the volume of CLL cells in an enlarged LN is $V_{\mathrm{CLL}, \mathrm{LN}}^{*}$ :

$$
V_{\mathrm{CLL}, \mathrm{LN}}^{*}=V_{\mathrm{CLL}, \mathrm{LN}}-V_{\mathrm{LN}}
$$

The number of CLL cells per $\mathrm{LN}\left((N+P)_{\mathrm{CLL}, \mathrm{LN}}\right)$ are calculated by dividing the volume of CLL cells $\left(\mathrm{V}_{\mathrm{CLL}}\right)$ in $\mathrm{LN}$ :

$$
(N+P)_{\mathrm{CLL}, \mathrm{LN}}=V_{\mathrm{CLL}, \mathrm{LN}}^{*} / V_{\mathrm{CLL}}
$$

Calculating the number of enlarged LN with diameter $\mathrm{d}_{\mathrm{LN}, \mathrm{CLL}}$ :

$$
N u_{\mathrm{LN}, d_{\mathrm{LN}, \mathrm{CLL}}}=\frac{N_{\mathrm{LN}}+P_{\mathrm{LN}}}{(N+P)_{\mathrm{CLL}, \mathrm{LN}}}
$$

\section{2) Size \& number of enlarged $L N$ with enlarged $S$ :}

(a) Calculating the total volume of $\mathrm{S}$ : Normally, $\mathrm{S}$ has diameter $\mathrm{d}_{\mathrm{S}, \mathrm{NC}} \approx 5 \mathrm{~cm}$ and length $\mathrm{l}_{\mathrm{S}, \mathrm{NC}} \approx 11$ $\mathrm{cm}$; splenomegaly severity is given in Table G.1. Assuming $\mathrm{S}$ is a cylinder, the $\mathrm{S}$ volume $\left(V_{\mathrm{S}}\right)$ is:

$$
V_{\mathrm{S}}=\pi(5 \mathrm{~cm} / 2)^{2} 11 \mathrm{~cm}=215.86 \mathrm{~cm}^{3}
$$

Eq (G.6) agrees with experiment, $V_{\mathrm{S}}=147.50 \pm$ $81.46 \mathrm{~cm}^{3}$ [50]. We assume that the normal lymphocyte count and the membrane volume are constant.

(b) Calculating the volume of enlarged $S$ and the number of CLL cells. The dimensions of the enlarged $\mathrm{S}$ are given by the physician. If the measured thickness of the enlarged $\mathrm{S}$ is $d_{\mathrm{S} \text {, CLL }}$ and its measured length is $l_{\mathrm{S} \text {, CLL }}$, the volume of CLL cells in $\mathrm{S}\left(V_{\mathrm{CLL}, \mathrm{S}}\right)$ is given by:

$$
V_{\mathrm{CLL}, \mathrm{S}}=\pi\left(d_{\mathrm{S}, \mathrm{CLL}} / 2\right)^{2} l_{\mathrm{S}, \mathrm{CLL}}-V_{\mathrm{S}}
$$

The number of CLL cells are calculated $(N+$ $P)_{\mathrm{CLL}, \mathrm{S}}$, by dividing the volume of CLL cells in $\mathrm{S}$ with the volume of one CLL cell:

$$
(N+P)_{\mathrm{CLL}, \mathrm{s}}=V_{\mathrm{CLL}, \mathrm{s}} / V_{\mathrm{CLL}}
$$

For cases with enlarged $\mathrm{S}$, the number of enlarged LN is calculated by subtracting the number of CLL 
cells in S from the total number of CLL cells and repeating the steps for calculating $\mathrm{Nu}_{\mathrm{LN}, d_{\mathrm{LN}, \mathrm{CLL}}}$.

\section{APPENDIX H \\ INITIALIZATION}

Because the Appendix D procedure begins with solving a feasibility problem, there are multiple starting points for the algorithm. We cannot prove that the algorithm will always converge to the same point, but this section demonstrates our computational experience that results of the Appendix D algorithm give answers within $10 \%$ of one another. Tables H.1 \& H.2 provide our computational experience with respect to patients P1 and P2. After initialising the GAMS feasibility problem 50 times, we had 4 distinct P1 feasible points (Table H.1) and 3 distinct P2 feasible points (Table H.2). Running the distinct points through the Appendix D algorithm changed some of the parameters (as illustrated with $\rightarrow$ in the tables). See in Fig H.1 that, although the lines are not identical, the trajectories are within $10 \%$.

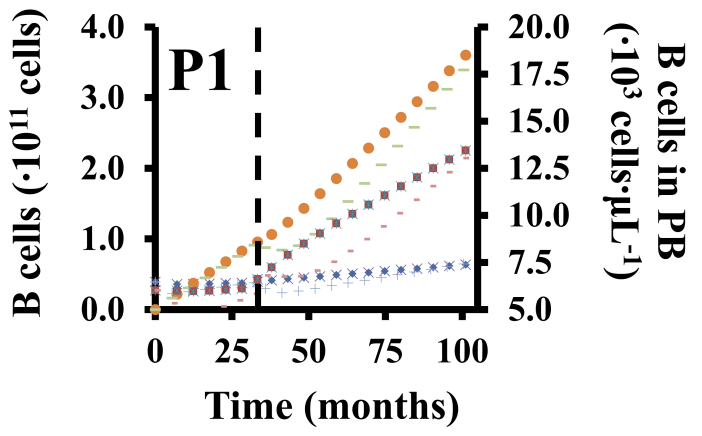

$\begin{array}{llll}\text { - BM_c_1 } & \text { LN_c_1 } & \times \text { BM_c_2 } & \text { - LN_c_2 } \\ - \text { LN_c_3 } & =\text { PB_c_1 } & * \text { PB_c_2 } & - \text { PB_c_3 }\end{array}$

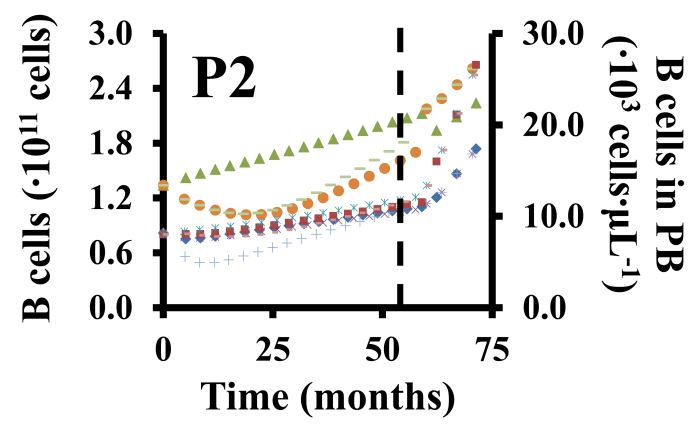

- BM_c_1 $\Delta$ LN_c_1 $\times$ BM_c_2 - LN_c_2 + BM_c_3
- LN_c_3 $=$ PB_c_1 $*$ PB_c_2 - PB_c_3

Fig. H.1: Disease trajectories of P1 and P2 after multistarting the Appendix D algorithm; observe that the trajectories are similar 
TABLE H.1: Results of an initial multistart strategy: Patient 1

\begin{tabular}{|c|c|c|c|c|c|c|c|c|c|}
\hline & & \multicolumn{2}{|r|}{ Case 1} & \multicolumn{2}{|c|}{ Case 2} & \multicolumn{2}{|c|}{ Case 3} & \multicolumn{2}{|c|}{ Case 4} \\
\hline & & Initial & Final & Initial & Final & Initial & Final & Initial & Final \\
\hline Transitions & & Naïve & A & Naïve & A & Naïve & A & Naïve & A \\
\hline$\gamma_{\mathrm{BM}}$ & 1/day & 0.796 & 1.000 & 0.796 & $0.001 \rightarrow 0.792$ & $0.004 \rightarrow 0.724$ & $0.002 \rightarrow 0.767$ & 0.774 & 0.774 \\
\hline$\gamma_{\mathrm{LN}}$ & 1/day & 1.000 & $0.844 \rightarrow 0.858$ & $0.001 \rightarrow 0.867$ & 0.858 & 0.863 & $0.001 \rightarrow 0.857$ & 0.861 & 0.861 \\
\hline$\gamma_{\mathrm{PB}}$ & $1 /$ day & 0.001 & 0.008 & 0.001 & 0.001 & 0.001 & 0.001 & 0.001 & 0.001 \\
\hline$\delta_{\mathrm{BM}}$ & $1 /$ day & 0.001 & 0.001 & 0.001 & 0.001 & 0.004 & 0.002 & 0.001 & 0.001 \\
\hline$\delta_{\mathrm{LN}}$ & $1 /$ day & 0.001 & 0.001 & 0.001 & 0.001 & 0.001 & 0.001 & 0.001 & 0.001 \\
\hline$\delta_{\mathrm{PB}}$ & 1/day & 0.001 & 0.001 & 0.001 & 0.001 & 0.001 & 0.001 & 0.001 & 0.001 \\
\hline$\tau_{\mathrm{BM}}$ & day & 0.792 & 0.792 & 0.792 & 0.792 & 0.792 & 0.792 & 0.792 & 0.792 \\
\hline$\tau_{\mathrm{LN}}$ & day & 0.683 & 0.792 & 0.792 & 0.792 & 0.790 & 0.792 & 0.792 & 0.792 \\
\hline$\tau_{\mathrm{PB}}$ & day & 0.792 & 0.792 & 0.792 & 0.625 & 0.792 & 0.792 & 0.792 & 0.792 \\
\hline$\theta_{\mathrm{BM}, 1}$ & $\cdot 10^{8}$ cells & 0.008 & 0.031 & 0.008 & $0.012 \rightarrow 0.052$ & 0.052 & 0.058 & 0.008 & 0.029 \\
\hline$\theta_{\mathrm{BM}, 2}$ & $\cdot 10^{8}$ cells & 92.233 & 107.835 & 92.233 & 37.11 & 47.986 & 41.691 & 91.987 & 100.082 \\
\hline$\theta_{\mathrm{LN}, 1}$ & $\cdot 10^{8}$ cells & 0.279 & 0.368 & $0.059 \rightarrow 0.219$ & 0.368 & 0.265 & 0.438 & 0.265 & 0.372 \\
\hline$\theta_{\mathrm{LN}, 2}$ & $\cdot 10^{8}$ cells & 0.001 & 264.655 & 0.001 & 265.039 & 0.001 & 77.053 & 0.001 & 265.039 \\
\hline$\theta_{\mathrm{PB}, 1}$ & $\cdot 10^{8}$ cells & 0.001 & 0.008 & 0.001 & 0.008 & 0.001 & 0.008 & 0.001 & 0.008 \\
\hline$\theta_{\mathrm{PB}, 2}$ & $\cdot 10^{8}$ cells & 15.000 & 16.450 & 15.000 & 16.450 & 15.000 & 16.450 & 15.000 & 16.450 \\
\hline$k_{\mathrm{N}, \mathrm{BM} 2 \mathrm{~PB}}$ & 1/day & 0.003 & 0.002 & 0.003 & 0.002 & 0.003 & 0.002 & 0.003 & 0.003 \\
\hline$k_{\mathrm{P}, \mathrm{BM} 2 \mathrm{~PB}}$ & $1 /$ day & 0.003 & 0.001 & 0.003 & 0.001 & 0.001 & 0.001 & 0.003 & 0.001 \\
\hline$k_{\mathrm{N}, \mathrm{PB} 2 \mathrm{LN}}$ & $1 /$ day & 0.003 & 0.001 & 0.003 & 0.001 & 0.003 & 0.002 & 0.003 & 0.002 \\
\hline$k_{\mathrm{P}, \mathrm{PB} 2 \mathrm{LN}}$ & 1/day & 0.025 & 0.001 & 0.033 & 0.007 & 0.008 & 0.007 & 0.033 & 0.007 \\
\hline
\end{tabular}

TABLE H.2: Results of an initial multistart strategy: Patient 2

\begin{tabular}{|c|c|c|c|c|c|c|c|}
\hline & & \multicolumn{2}{|c|}{ Case 1} & \multicolumn{2}{|c|}{ Case 2} & \multicolumn{2}{|l|}{ Case 3} \\
\hline & & Initial & Final & Initial & Final & Initial & Final \\
\hline \multicolumn{2}{|c|}{ Transitions } & $\mathrm{A}$ & B & A & B & A & B \\
\hline$\gamma_{\mathrm{BM}}$ & 1/day & 0.770 & 0.740 & $0.796 \rightarrow 0.823$ & 0.740 & $0.002 \rightarrow 0.794$ & 0.091 \\
\hline$\gamma_{\mathrm{LN}}$ & 1/day & $1.000 \rightarrow 0.995$ & $0.002 \rightarrow 0.619$ & $0.001 \rightarrow 0.859$ & $0.855 \rightarrow 0.860$ & $0.001 \rightarrow 0.858$ & 0.860 \\
\hline$\gamma_{\mathrm{PB}}$ & 1/day & 0.001 & 0.001 & 0.005 & 0.001 & 0.001 & 0.003 \\
\hline$\delta_{\mathrm{BM}}$ & 1/day & 0.001 & 0.001 & 0.001 & 0.001 & 0.002 & 0.034 \\
\hline$\delta_{\mathrm{LN}}$ & 1/day & 0.001 & 0.020 & 0.001 & 0.001 & 0.001 & 0.001 \\
\hline$\delta_{\mathrm{PB}}$ & 1/day & 0.001 & 0.001 & 0.001 & 0.003 & 0.001 & 0.003 \\
\hline$\tau_{\mathrm{BM}}$ & day & 0.792 & 0.792 & 0.792 & 0.792 & 0.792 & 0.792 \\
\hline$\tau_{\mathrm{LN}}$ & day & 0.699 & 0.792 & 0.792 & 0.792 & 0.792 & 0.792 \\
\hline$\tau_{\mathrm{PB}}$ & day & 0.625 & 0.625 & 0.625 & 0.625 & 0.792 & 0.625 \\
\hline$\theta_{\mathrm{BM}, 1}$ & $\cdot 10^{8}$ cells & 0.057 & 0.526 & 0.057 & 0.522 & 0.118 & 0.481 \\
\hline$\theta_{\mathrm{BM}, 2}$ & $\cdot 10^{8}$ cells & 173.123 & 274.733 & 173.649 & 274.325 & 80.337 & 258.275 \\
\hline$\theta_{\mathrm{LN}, 1}$ & $\cdot 10^{8}$ cells & 0.162 & $-0.193 \rightarrow 0.293$ & $0.025 \rightarrow 0.225$ & 0.450 & 0.256 & 0.451 \\
\hline$\theta_{\mathrm{LN}, 2}$ & $\cdot 10^{8}$ cells & 344.553 & 524.785 & 87.137 & 607.614 & 87.120 & 607.436 \\
\hline$\theta_{\mathrm{PB}, 1}$ & $\cdot 10^{8}$ cells & 0.007 & 0.104 & 0.007 & 0.104 & 0.007 & 0.104 \\
\hline$\theta_{\mathrm{PB}, 2}$ & $\cdot 10^{8}$ cells & 20.000 & 33.05 & 20.000 & 33.05 & 20.000 & 33.05 \\
\hline$k_{\mathrm{N}, \mathrm{BM} 2 \mathrm{~PB}}$ & 1/day & 0.003 & 0.004 & 0.001 & 0.004 & 0.001 & 0.004 \\
\hline$k_{\mathrm{P}, \mathrm{BM} 2 \mathrm{~PB}}$ & 1/day & 0.001 & 0.004 & 0.001 & 0.001 & 0.001 & 0.001 \\
\hline$k_{\mathrm{N}, \mathrm{PB} 2 \mathrm{LN}}$ & 1/day & 0.005 & 0.003 & 0.001 & 0.001 & 0.001 & 0.001 \\
\hline$k_{\mathrm{P}, \mathrm{PB} 2 \mathrm{LN}}$ & 1/day & 0.013 & 0.046 & 0.014 & 0.009 & 0.013 & 0.007 \\
\hline
\end{tabular}

